\title{
PRIVATE SECTOR PARTCIPATION IN YEMEN NATIONAL ECONOMY
}

Shobeer A. A. Elharazi

Dept. of Agric. Economic, Fac. of Agric., Sanaa Univ.

مشاركة الفَطاع الخاص في صنع السياسات العامة بالجمهورية اليمنية

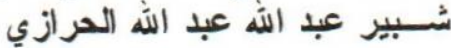

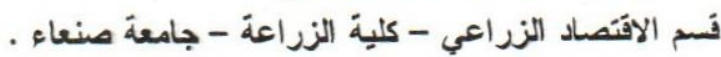
بريــ إلكترونــي : alharazi63@yahoo.com \& alharazi63@ hotmail.com

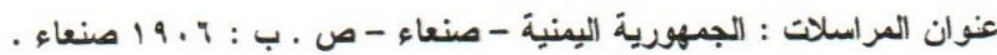

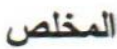

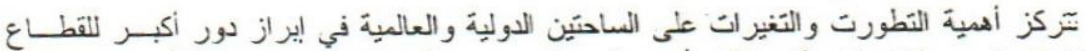

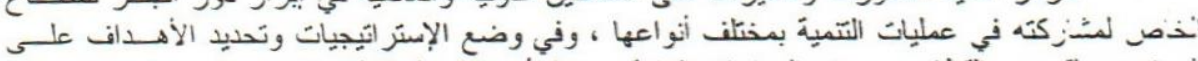

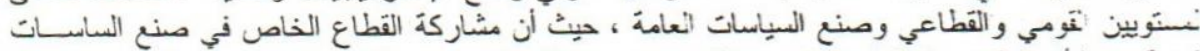

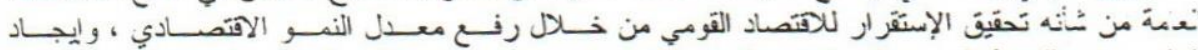

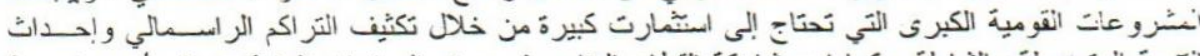

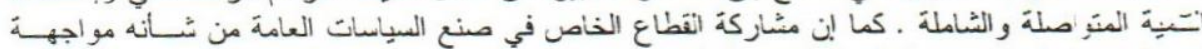

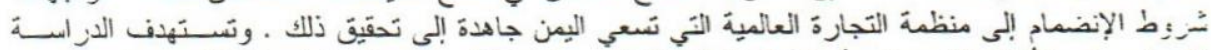

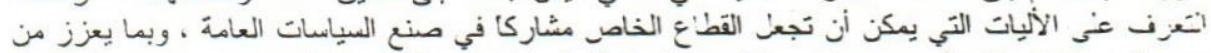

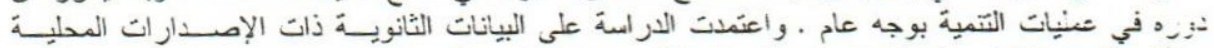

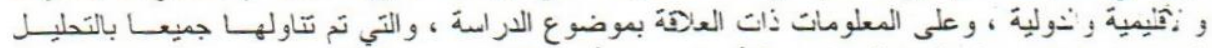

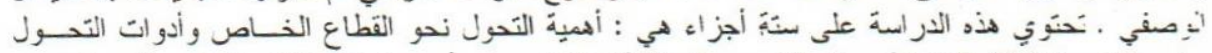

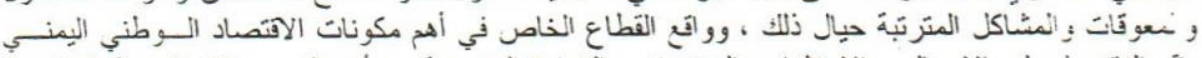

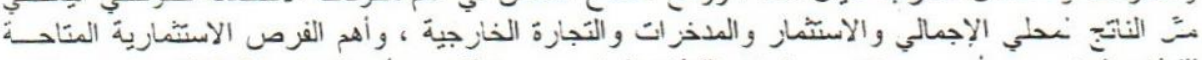

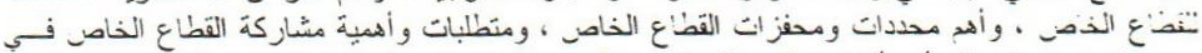

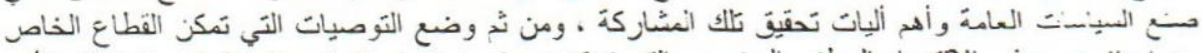

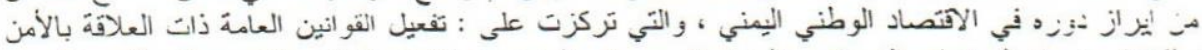

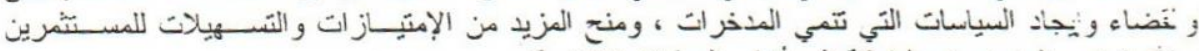

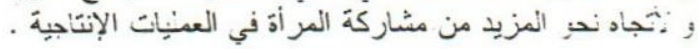

\section{المقدمة}

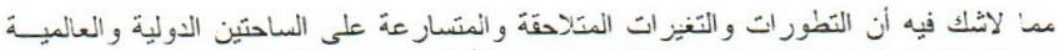

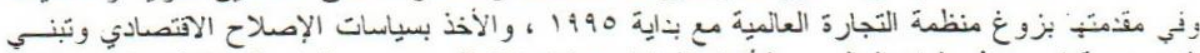

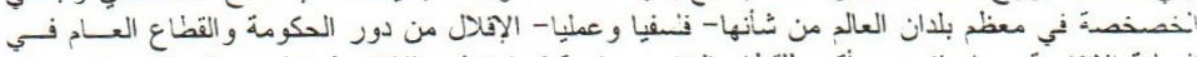

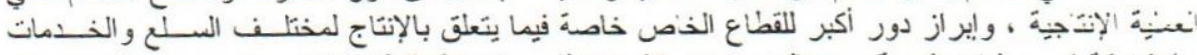

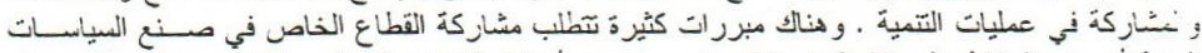

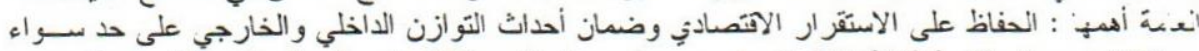

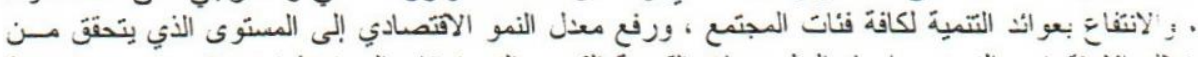

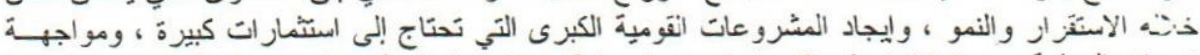

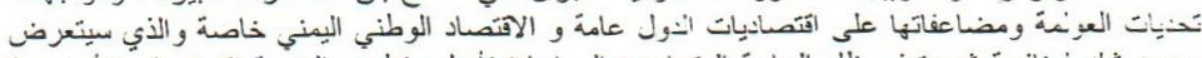

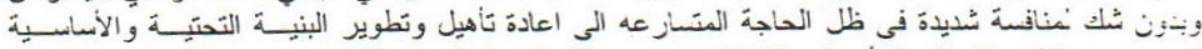

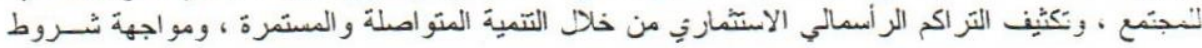




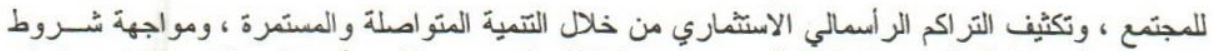

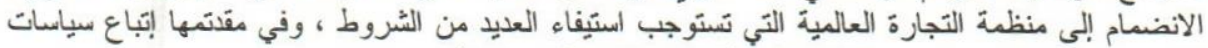

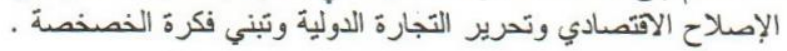

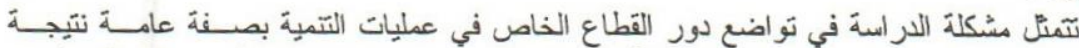
مشكلة الار اسه:

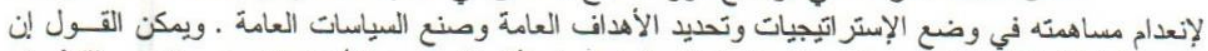

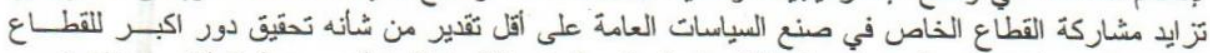

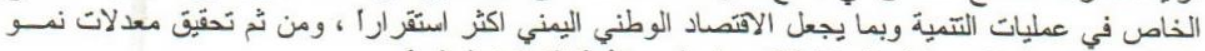

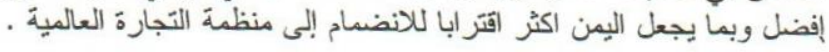

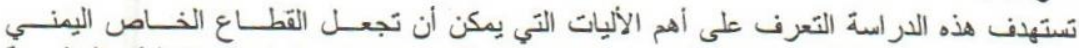
التهدف من الاراسه:

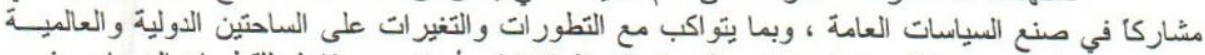

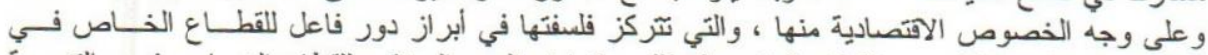

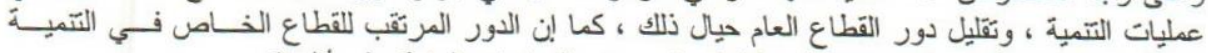

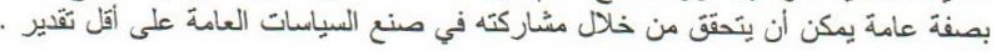

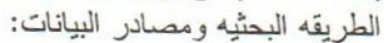

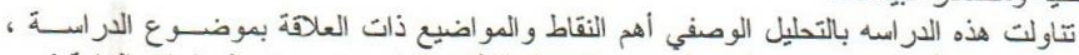

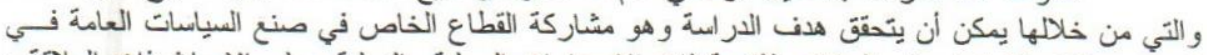

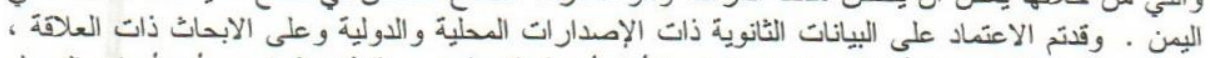

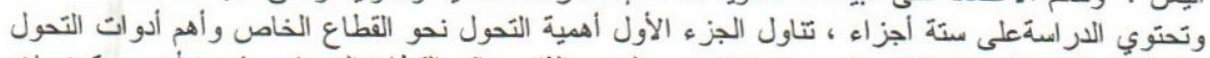

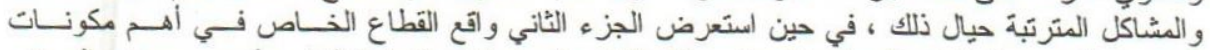

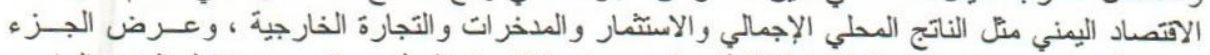

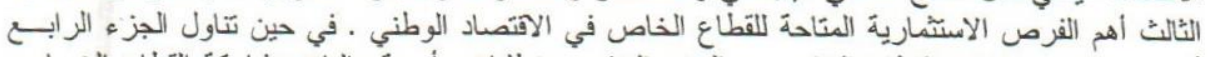

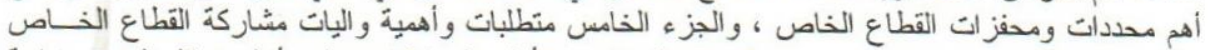

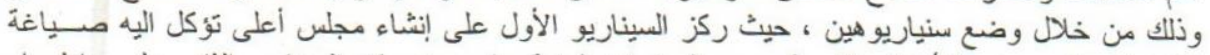

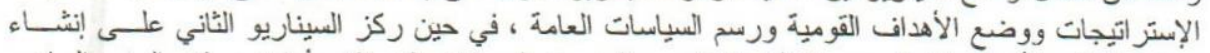

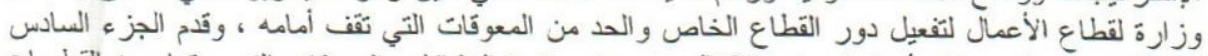

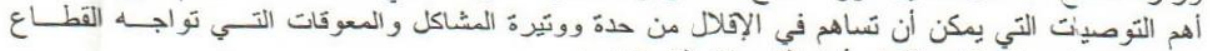

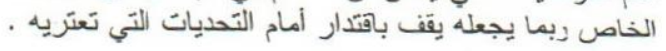

أولا : التحول نحو القطاع الخاص

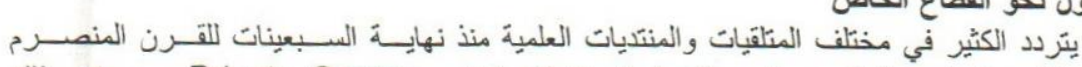

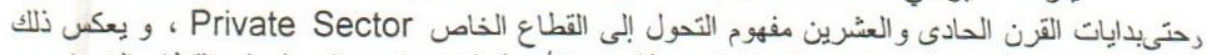

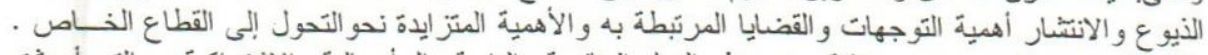

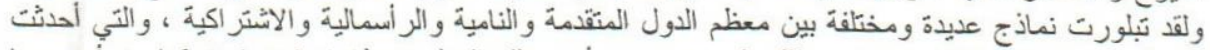

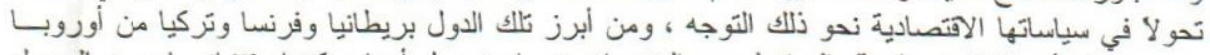

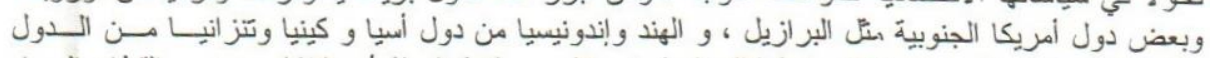

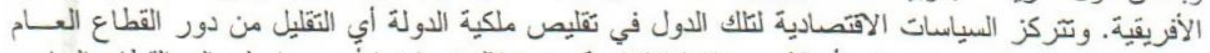

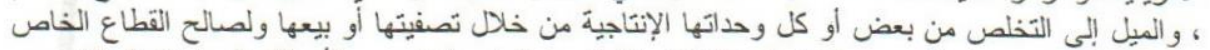

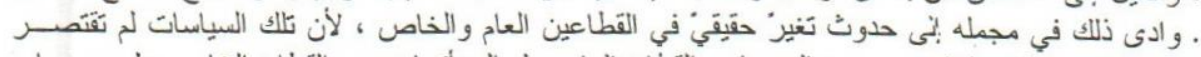

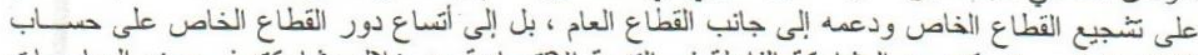

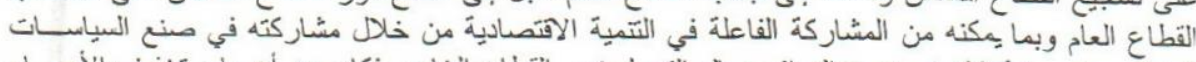

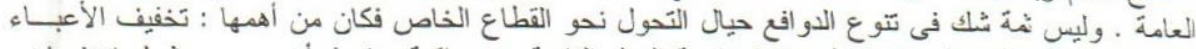

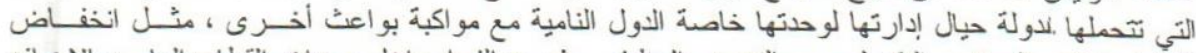

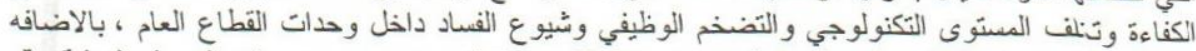

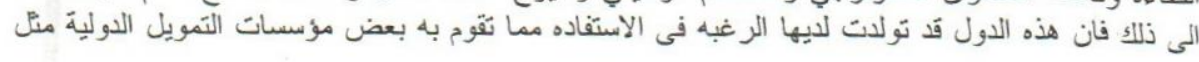




\section{J. Agric. Sci. Mansoura Univ., 29 (8), August, 2004}

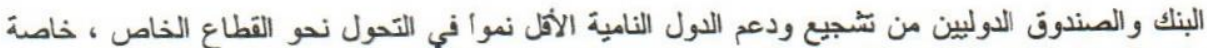

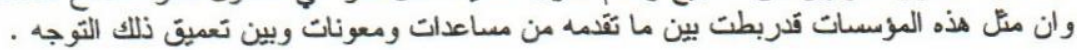

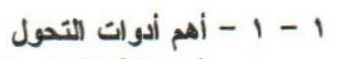

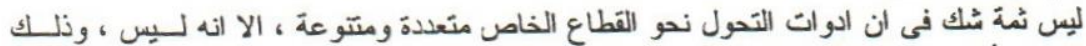

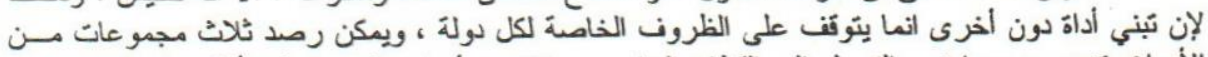

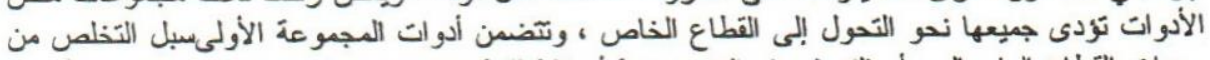

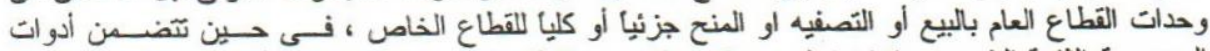

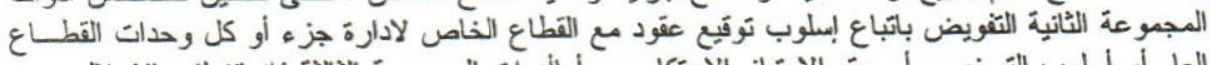

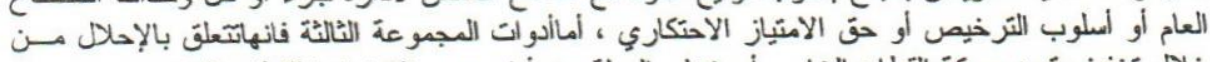

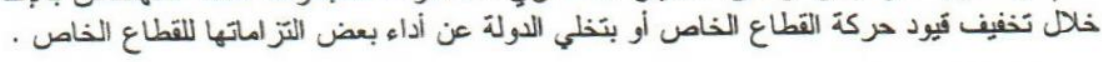

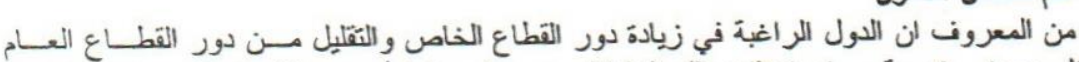

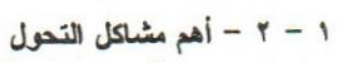

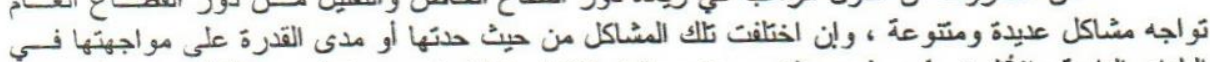

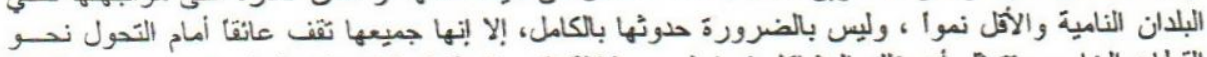

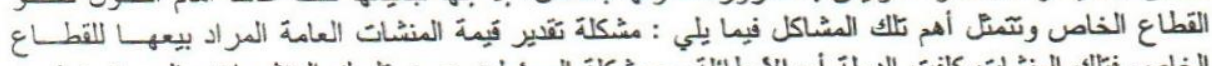

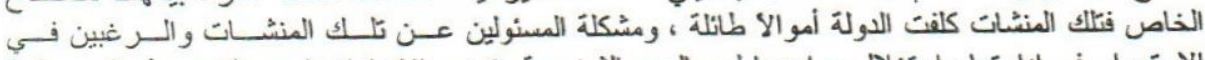

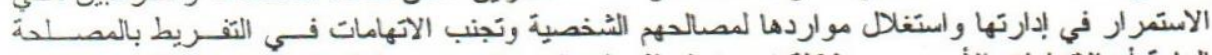

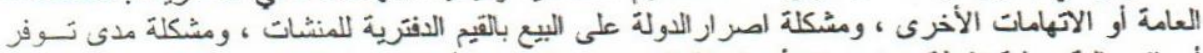

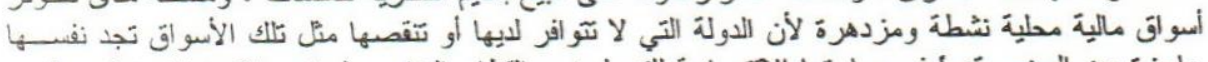

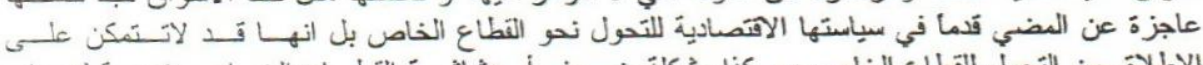

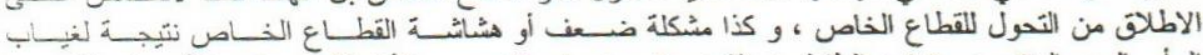

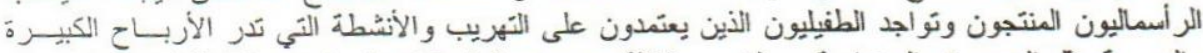

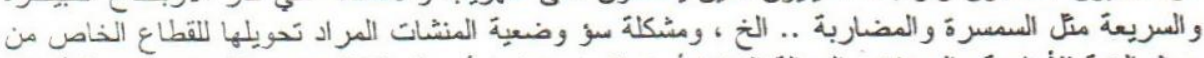

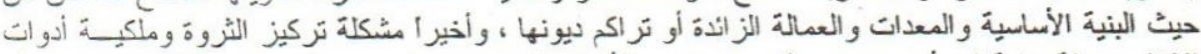

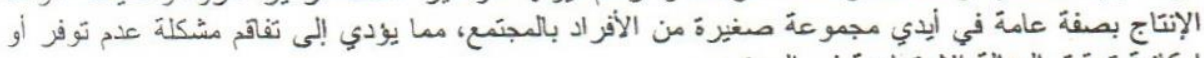

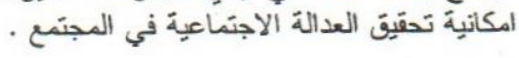

ثاتيا : واقع القطاع الخاص في الاقتصاد اليمني

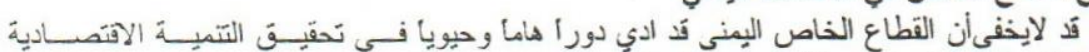

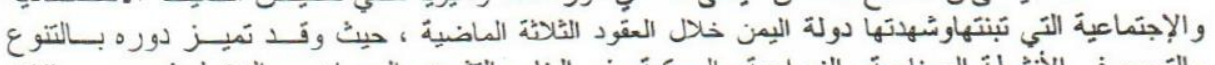

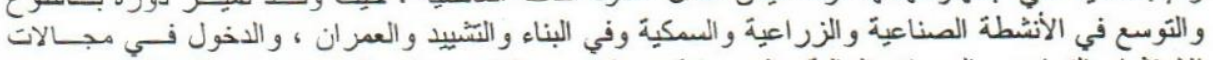

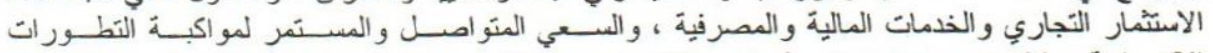

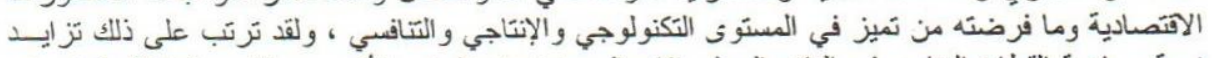

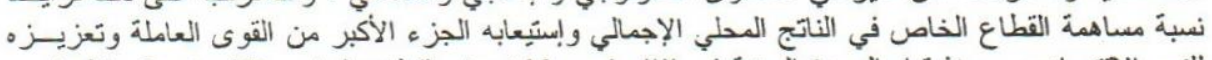

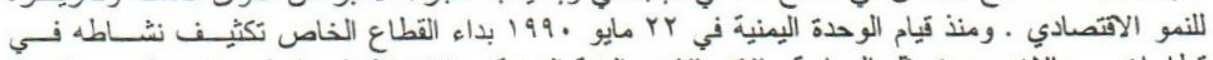

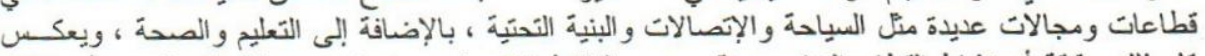

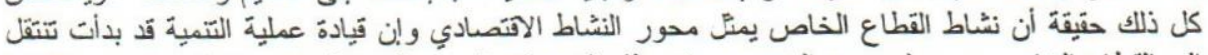

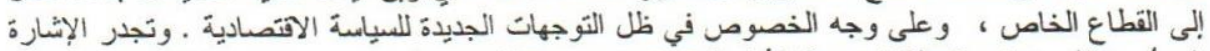

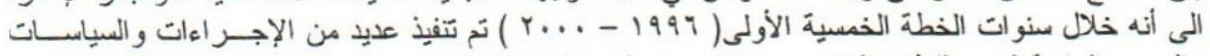

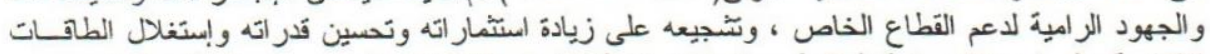

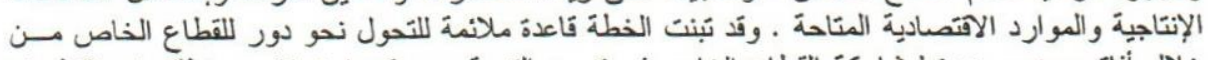

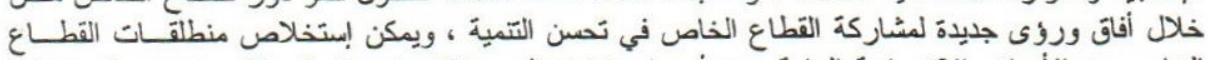

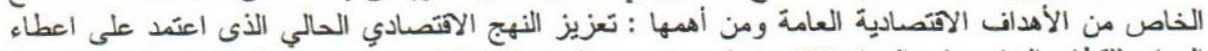

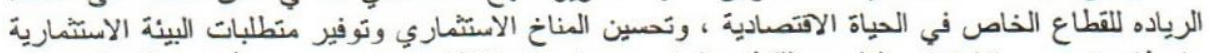

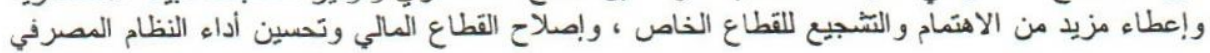




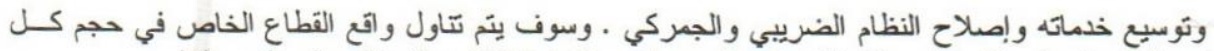
من الناتج المحلي الإجمالي والاسشّمار ات والمدخرات والتجارة الخارجية وذلك على النحو التالى لئ.

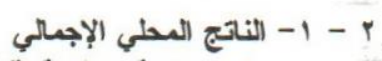

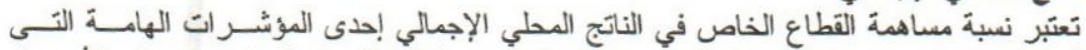

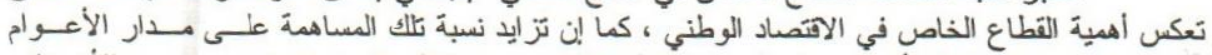

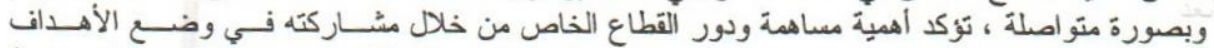

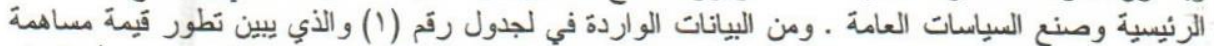

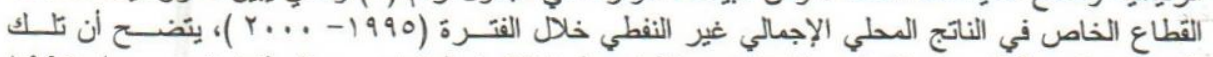

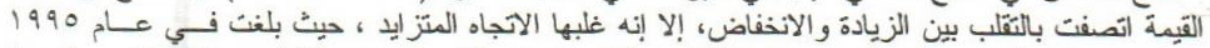

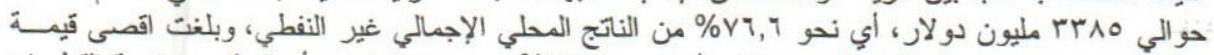

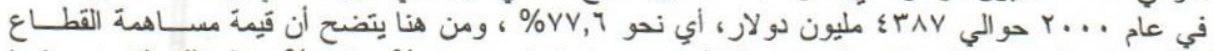

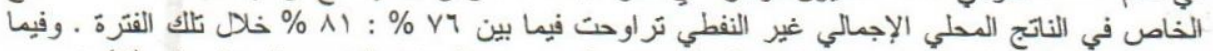

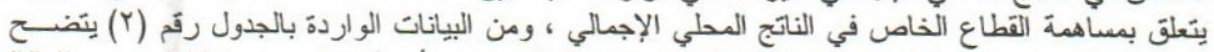

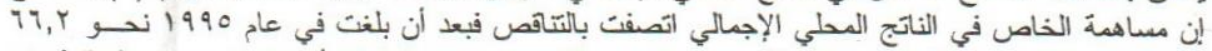

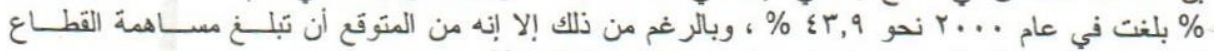

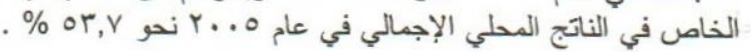

جدول رقم ( 1 ) : تطور قيمة مساهة القطاع الخاص في الناتج المحلي الإجمالمي غير النفطي خلا الفترة ( القيمة بالمليون دولار )

\begin{tabular}{|c|c|c|c|c|c|c|}
\hline$r \ldots$ & 1999 & 1991 & 1998 & 1997 & 1990 & السبنوات \\
\hline$\{\Gamma \wedge \uparrow, q$ & $\varepsilon \ldots r, \wedge$ & §।Y $Y, Y$ & $\varepsilon \ldots 9,1$ & rrrq,६ & 3385.0 & القطاع الخاص \\
\hline$V Y, T$ & $\mathrm{VY}, \mathrm{T}$ & $\mathrm{VA}, 0$ & $1 \cdot, 0$ & VA,r & Vา, 1 & (\%) \\
\hline Ir77,r & $1100, Y$ & $11 T \cdot, r$ & $9 \times 1,0$ & $9 Y Y, A$ & 1034.0 & القطاع العام والحكومي \\
\hline$r Y, \xi$ & $Y Y, \xi$ & $r 1,0$ & 19,0 & $r 1, Y$ & $r r, \xi$ & $(\%)$ \\
\hline $010 \mathrm{r}, \mathrm{r}$ & 0109,0 & OY07, \& & $\leqslant 9 \wedge \cdot, 7$ & EYOY,Y & 4419.0 & الإجمالي \\
\hline $171, \mathrm{Vr}$ & 100,10 & $1 r 0, r \Lambda$ & $\mid Y Q, Y \wedge$ & $1 Y \wedge, 19$ & 100.00 & سعر الصرف \\
\hline
\end{tabular}

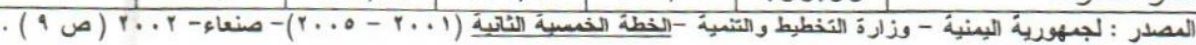

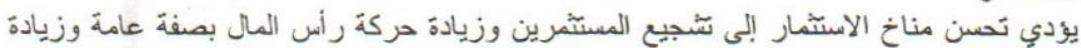

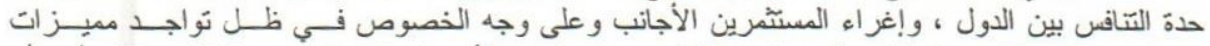

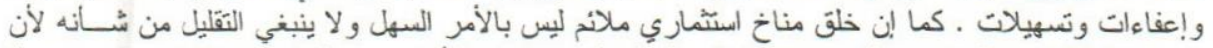

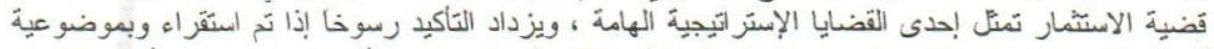

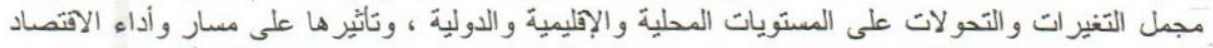

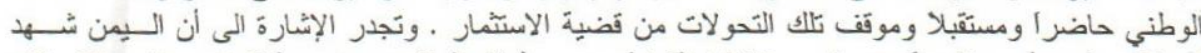

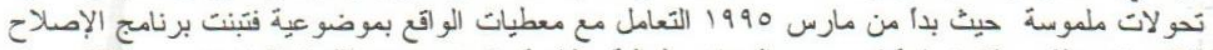

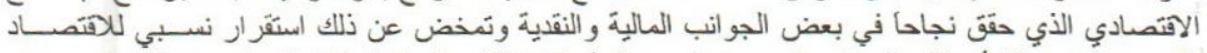

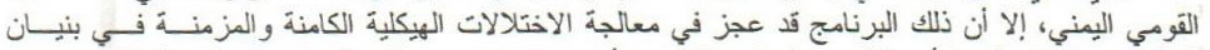

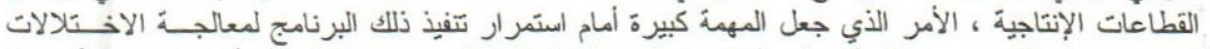

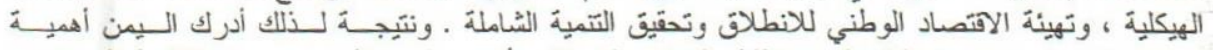

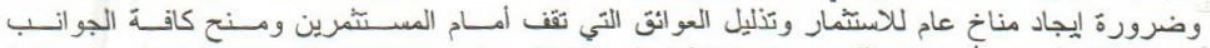

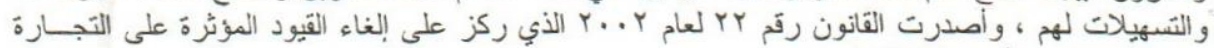
وحركة روؤس الأموال و انتقالها . 


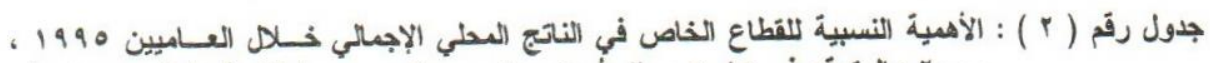

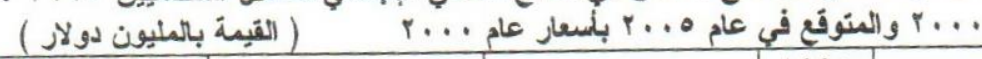

\begin{tabular}{|c|c|c|c|c|c|c|}
\hline \multirow{2}{*}{ 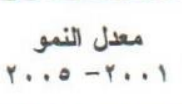 } & \multicolumn{2}{|c|}{$r \ldots o$} & \multicolumn{2}{|c|}{$r \ldots$} & \multirow{2}{*}{$\begin{array}{c}1990 \\
\%\end{array}$} & \multirow{2}{*}{ 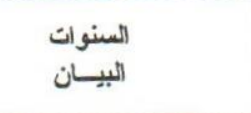 } \\
\hline & $\%$ & القيمة & $\%$ & القيمة & & \\
\hline$\Lambda, \cdot$ & $v \leqslant, r$ & ArYo, T & $79, r$ & oror, 0 & 17,0 & أولا:التطاع غير النفطي \\
\hline$\varepsilon, V$ & $1 \cdot, 2$ & $117 r, 2$ & $1 \cdot, 1$ & Irr, & $r$ r., & • الحكومي والعام \\
\hline 9,1 & or, v & $7.1 \mathrm{~V}$, & $\varepsilon r, q$ & rV $\leqslant 1,7$ & $77, r$ & • \\
\hline$\cdots$ & YO, Y & $r \wedge \vee \wedge, r$ & $r, v$ & $r \wedge \vee \wedge, 1$ & 17,0 & ثانياً :التططاع النفطي \\
\hline 0,1 & $1 \ldots$ & $11 r \cdot r, 9$ & $1 \cdots$ & Norl, 1 & $1 \ldots$ & الاجمالي \\
\hline
\end{tabular}

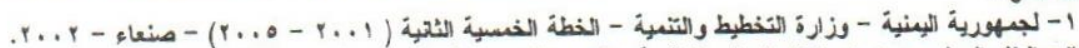

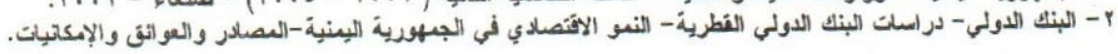

وبالر غم من تلك الجهود التي بذلت لتحسين مناخ الآشيّار ، إلا أنه ماز ال هناك الكثير مما ينبغي

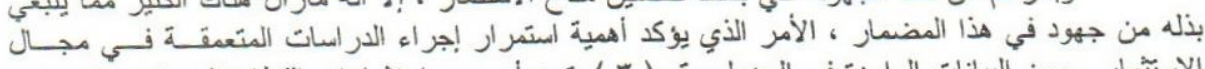

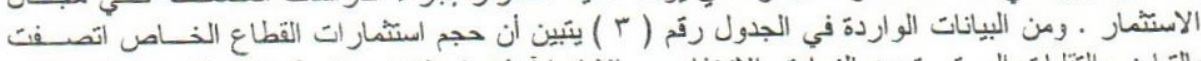

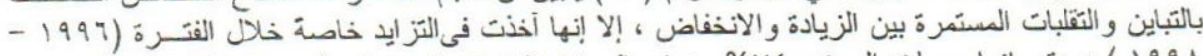

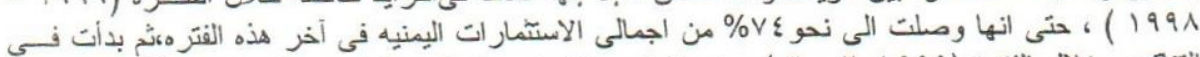

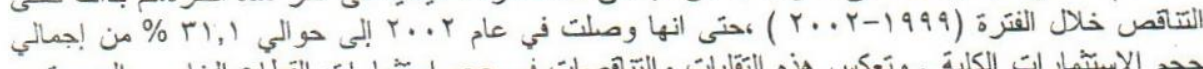

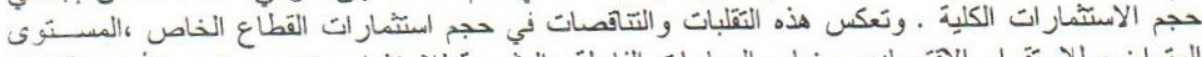

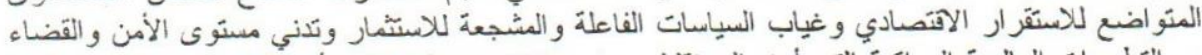

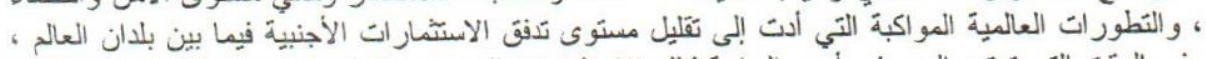

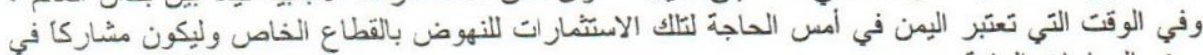

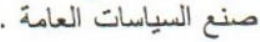

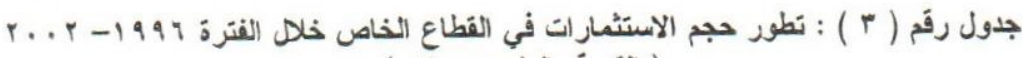

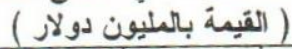

\begin{tabular}{|c|c|c|c|c|c|c|c|}
\hline$r \ldots r$ & $r \ldots 1$ & $r \ldots$ & 1999 & 1991 & 1998 & 1997 & $\begin{array}{l}\text { البيانوات } \\
\text { البيات }\end{array}$ \\
\hline $177 \cdot, \mathrm{Y}$ & $17 \leqslant \Lambda$, & YrOO, & $|\vee \wedge \wedge|$, & $Y \cdot \leq Y, \varepsilon$ & $1 V 11,0$ & IrTr, & الاستشمار الإجمالي \\
\hline $11 \leqslant r, r$ & 119,0 & $1 Y \leqslant 0,9$ & $0 \wedge \mathrm{V}, 0$ & or 1,1 & $7 \cdot 1,1$ & $\leqslant \vee 0$, & • • الاستَمار العام \\
\hline 71,9 & $\varepsilon q, \vee$ & or, 9 & $r, q$ & $r T, \cdot$ & $r 0, r$ & $r 0, i$ & $(\%)$ \\
\hline $01 \mathrm{~V}$, & $\Lambda Y \Lambda, 0$ & $11.9,9$ & IT $\cdots, T$ & $101 \cdot, 7$ & $11 \cdot 9, r$ & $\Lambda 0 \Lambda, r$ & • الاســ ـ لــمار \\
\hline ri,l & $0 ., r$ & $\leqslant \mathrm{~V}, 1$ & $7 V, 1$ & $v \leqslant, \cdot$ & $i \varepsilon, \wedge$ & $T \leq, \varsigma$ & الخاص ) \\
\hline
\end{tabular}

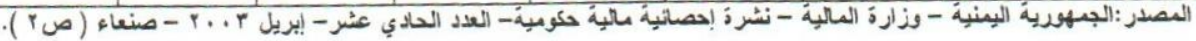

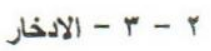

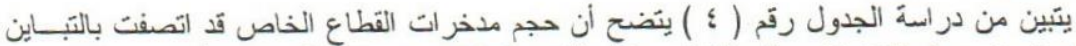

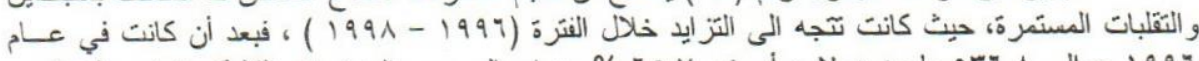

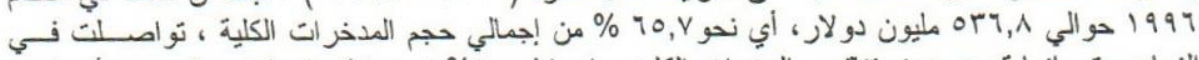

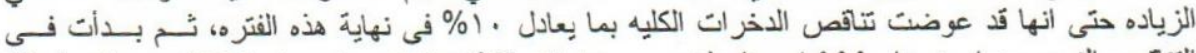

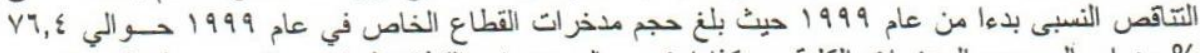

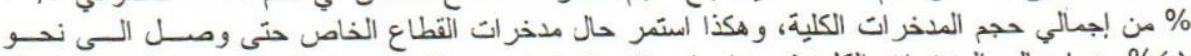

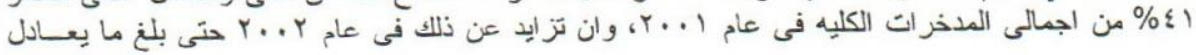




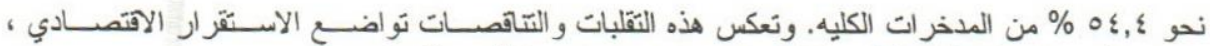

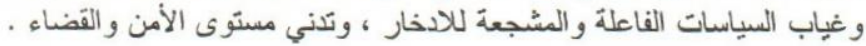

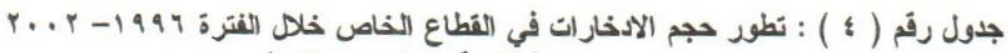

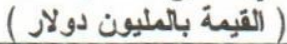

\begin{tabular}{|c|c|c|c|c|c|c|c|}
\hline$r \ldots r$ & $r \ldots l$ & $r \ldots$ & 1999 & 1991 & 1998 & 1997 & $\begin{array}{l}\text { اللينوان } \\
\text { البيان }\end{array}$ \\
\hline $1 \leqslant 0 r, A$ & lors, 9 & $r Y \circ 0, T$ & $171 \cdot r$ & Vrr,o & $11 \cdot 9, r$ & A) $7, \wedge$ & الإدمالي \\
\hline 7ד,. & $9.1,5$ & $1 Y \leqslant 0,9$ & rᄉ , ह & $V Y, \varepsilon-$ & $r+, r$ & $r \wedge \cdot, \cdot$ & \multirow{2}{*}{ 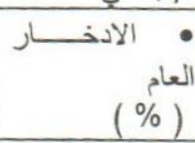 } \\
\hline$\{0,7$ & $0 \wedge, 7$ & or, 9 & $r r, T$ & $1 \cdot, \cdot-$ & $r q, \Lambda$ & $r \leqslant, r$ & \\
\hline 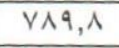 & $7 r v, 0$ & $11 \cdot 9,9$ & $1 Y Y \Lambda, 9$ & $1.0,9$ & VVA, 9 & ory, 1 & \multirow{2}{*}{ الادخار الخاص (\% } \\
\hline $0 \leqslant, \leqslant$ & $\{1,1$ & $\varepsilon \vee, 1$ & Vฯ, โ & $11 \cdot, \cdot$ & $V \cdot, r$ & $10, \mathrm{~V}$ & \\
\hline IV7, . & זוד, זד & זע, ו1, & 100,10 & גז, & $\mid r q, r \wedge$ & $1 \mathrm{rA}, 19$ & 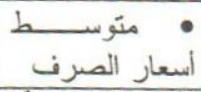 \\
\hline
\end{tabular}

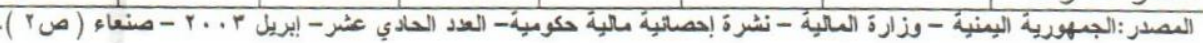

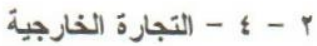

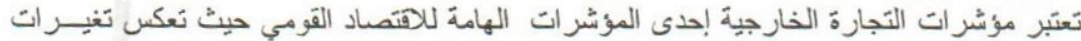

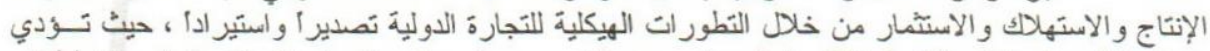

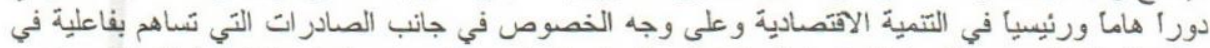

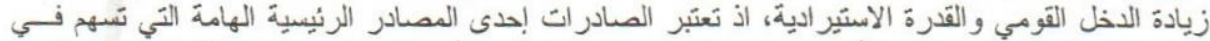

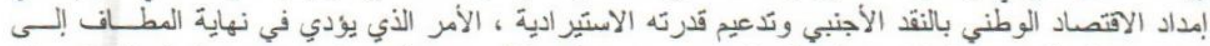

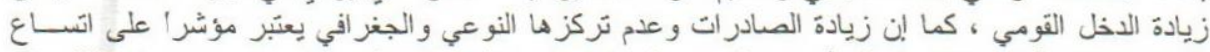

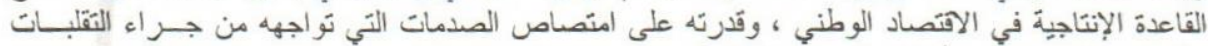

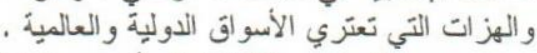

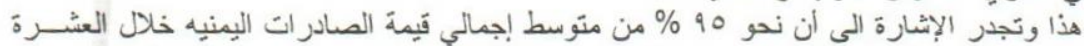

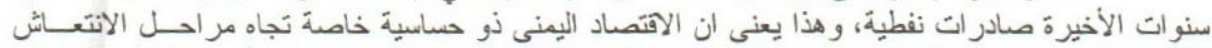

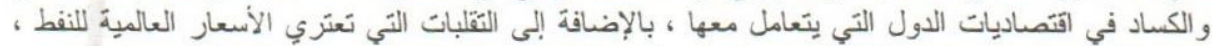

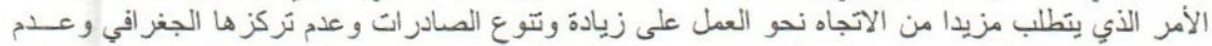

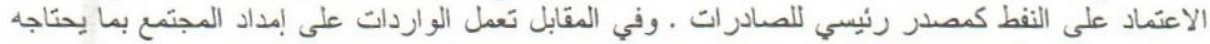

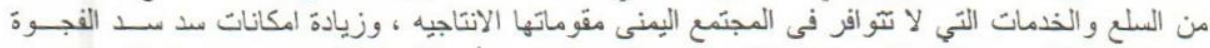

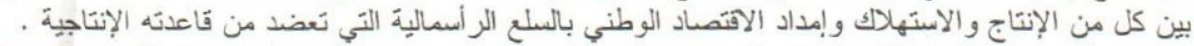

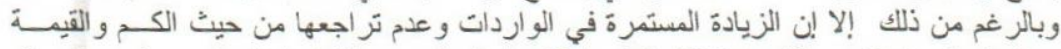

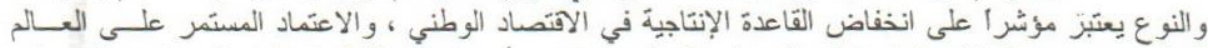

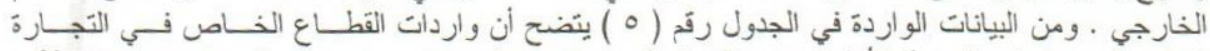

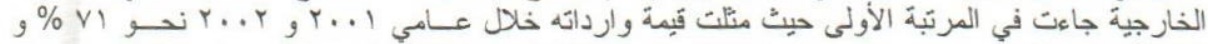

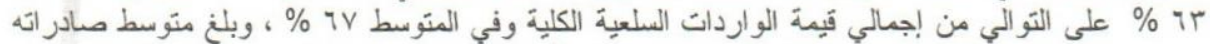

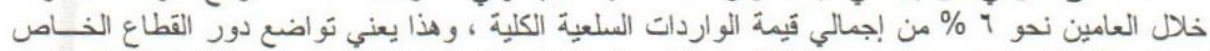

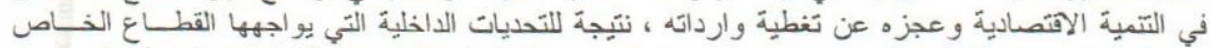

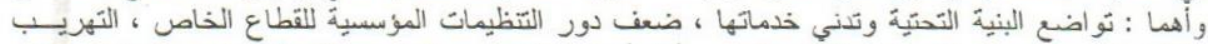

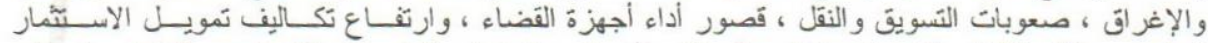

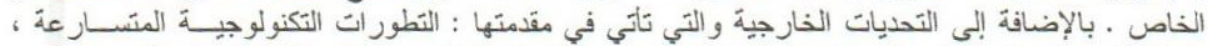

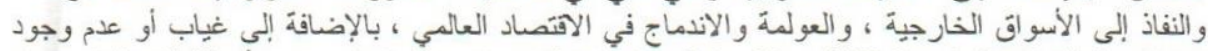

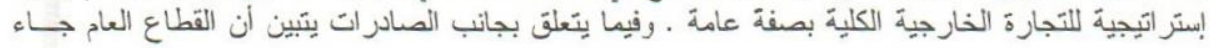




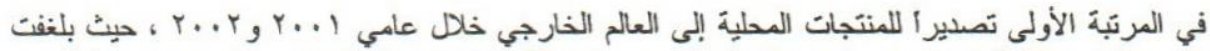

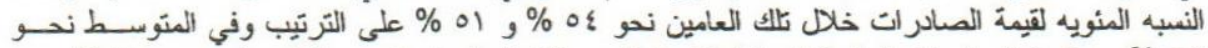

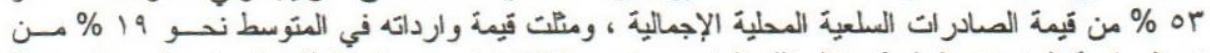

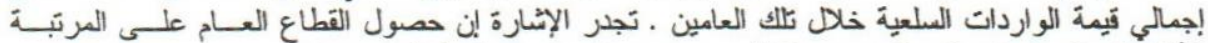

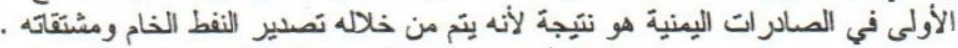

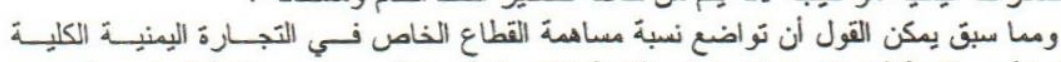

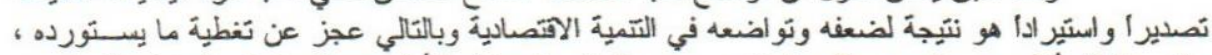

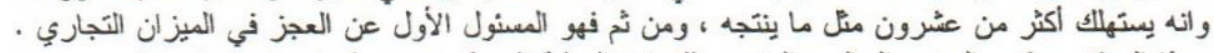

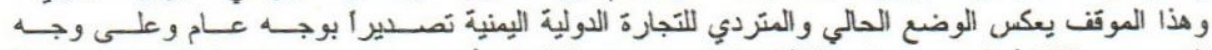

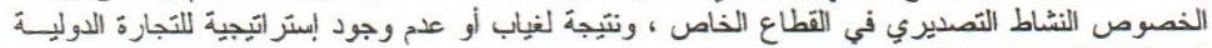
اليمنية الكلِية بصفة النفة عامة .

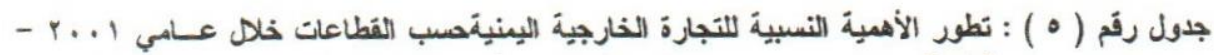

\begin{tabular}{|c|c|c|c|c|c|c|c|c|}
\hline \multicolumn{9}{|c|}{$r \ldots r$} \\
\hline \multicolumn{4}{|c|}{$r \ldots r$} & \multicolumn{4}{|c|}{$p \ldots l$} & \multirow{3}{*}{ السنوات } \\
\hline \multicolumn{2}{|c|}{ الصنادرات } & \multicolumn{2}{|c|}{ اللو اردات } & \multicolumn{2}{|c|}{ الصادرات } & \multicolumn{2}{|c|}{ الواردات } & \\
\hline الترتيب & $\%$ & الترتيب & $\%$ & الترنيب & $\%$ & الترتيب & $\%$ & \\
\hline 0 & $01, \cdot$ & $\varepsilon$ & $r, \cdot$ & 7 & $0 \leqslant, \cdot$ & $\leq$ & $r, \cdot$ & القططاع الحكومي \\
\hline 1 & & $r$ & rI, & 1 & - & $r$ & IV, & القطاع العام \\
\hline 7 & & 0 & 1,1 & $\varepsilon$ & - & 0 & 1,0 & القطاع المختط \\
\hline $\mathrm{V}$ & $\mathrm{V}$ & v & $\cdot, r$ & $\mathrm{~V}$ & 0 & $\mathrm{v}$ & $\cdot, r$ & القطاع التعاوني \\
\hline$r$ & $\varepsilon r$ & 1 & 7r,. & $r$ & $\varepsilon$ & 1 & VI, & القَطاع الخاص \\
\hline$r$ & & $r$ & $11, \cdot$ & $r$ & - & $r$ & $\wedge, \cdot$ & الشركات الأجنيبة \\
\hline$\varepsilon$ & & 7 & $\cdot, 7$ & 0 & - & 7 & $\cdot, \mathrm{V}$ & المنظمات الدولِية \\
\hline- & $1 \ldots$ & - & $1 \cdots$ & - & $1 \cdots$ & - & $1 \cdots$ & المجموع \\
\hline
\end{tabular}

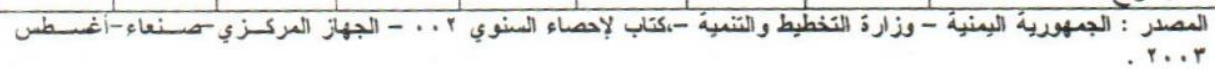

ثُلثا : أهم الفرص الاستثارية المتاحة

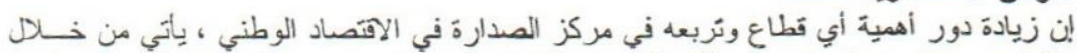

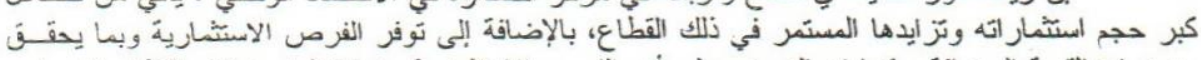

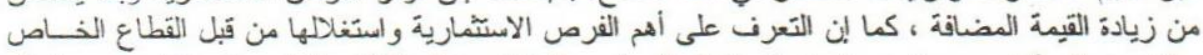

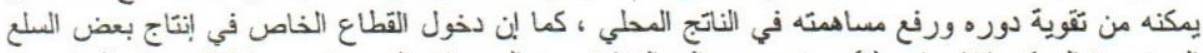

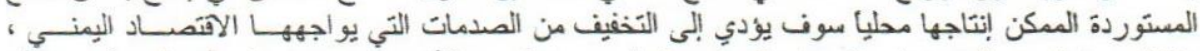

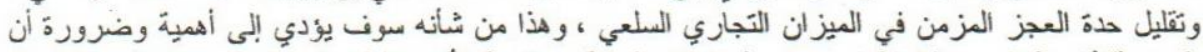

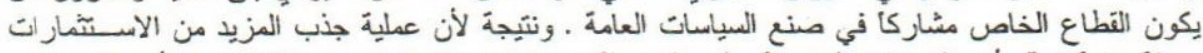

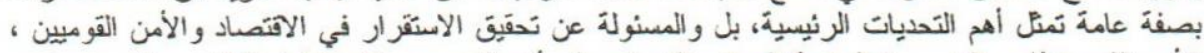

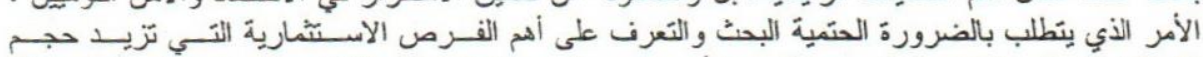

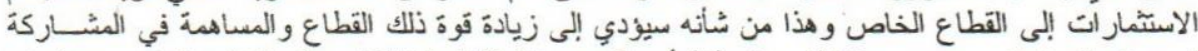

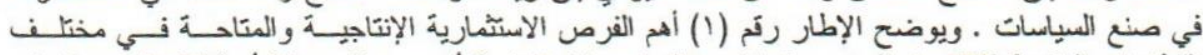

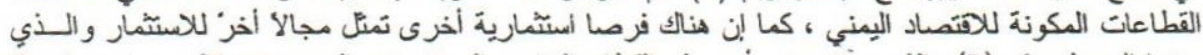

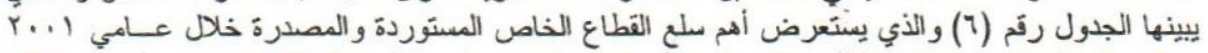

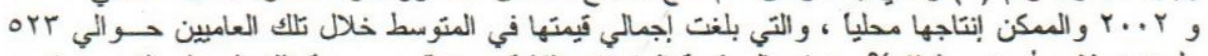

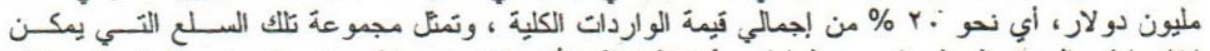

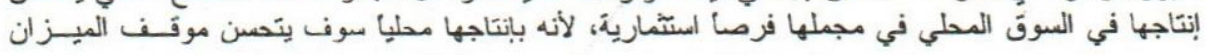




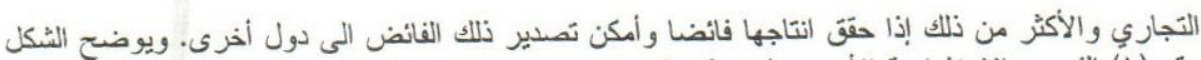

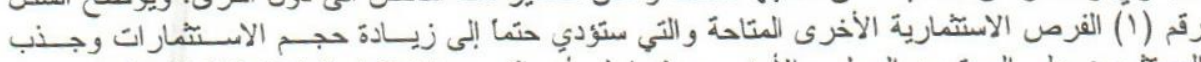

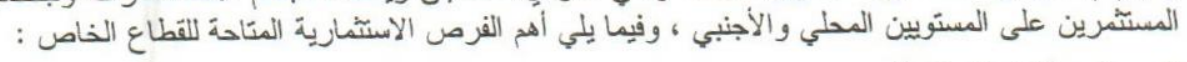

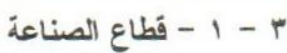

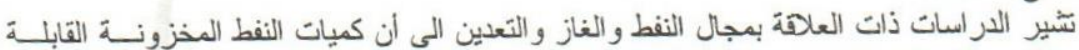

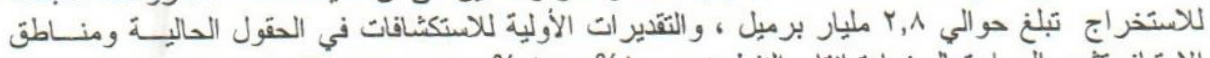

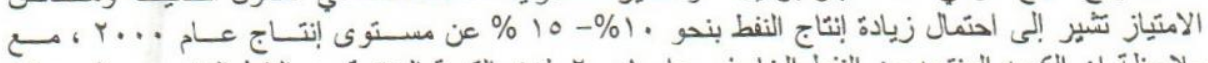

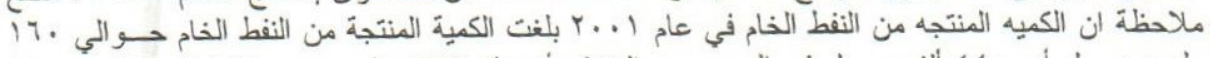

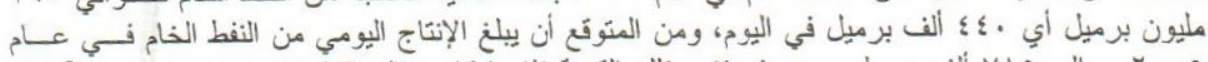

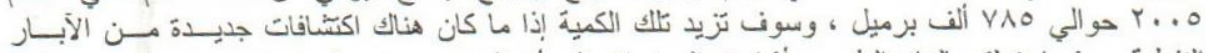

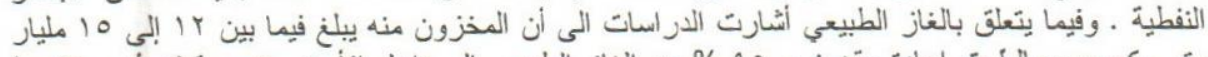

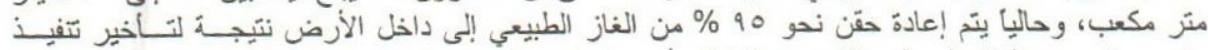

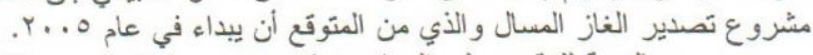

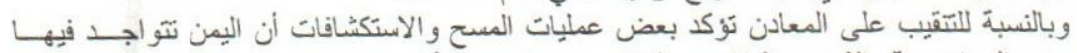

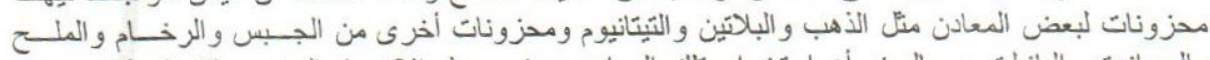

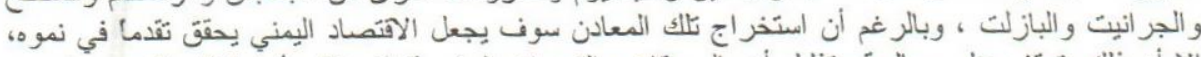

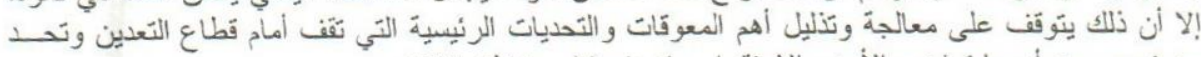

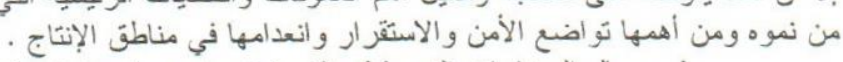

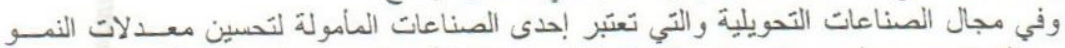

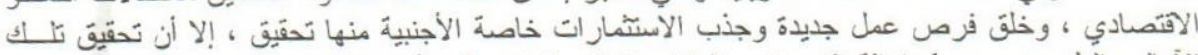

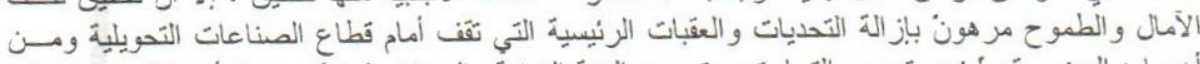

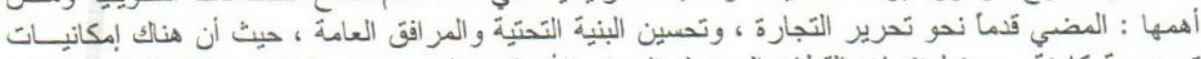

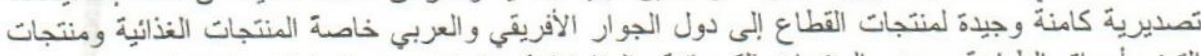

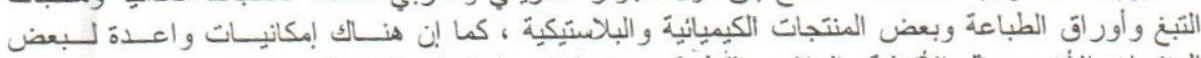

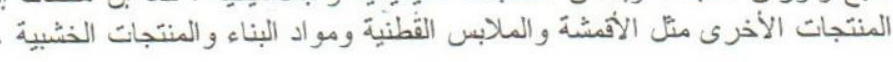

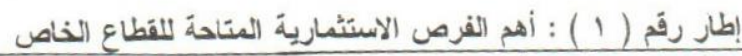

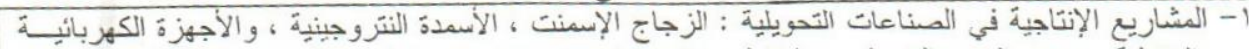

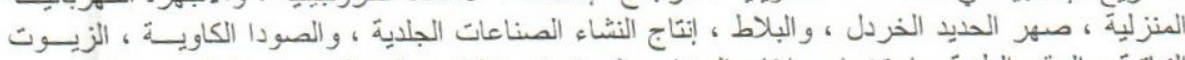

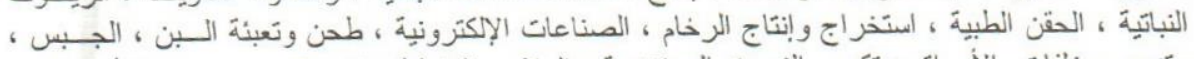

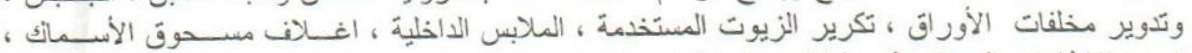

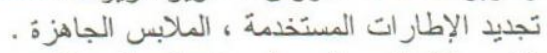

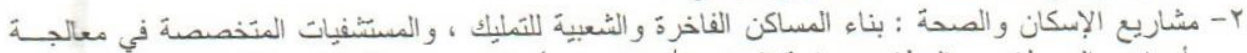

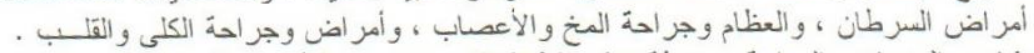

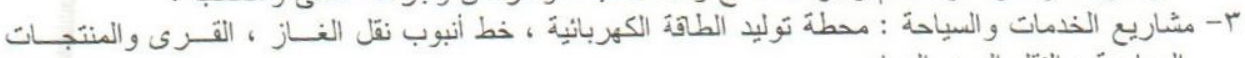

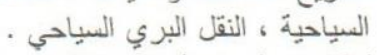

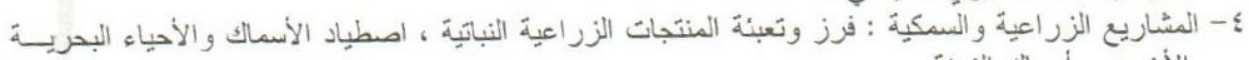

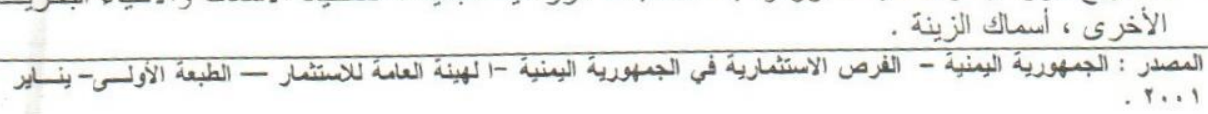

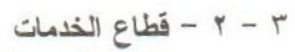

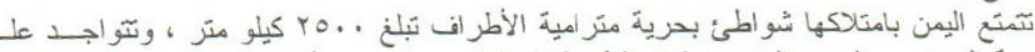

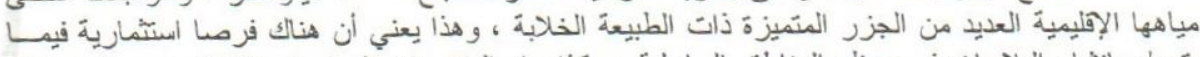

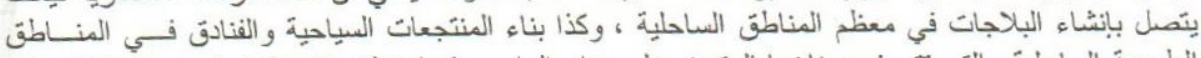

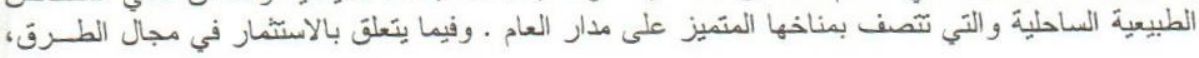




\section{J. Agric. Sci. Mansoura Univ., 29 (8), August, 2004}

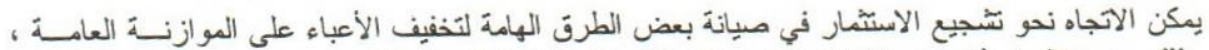

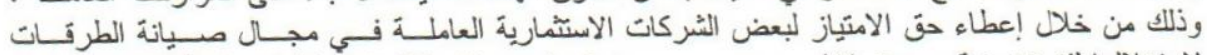

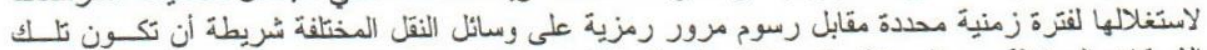

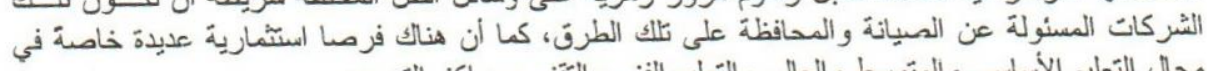

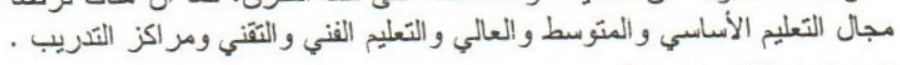

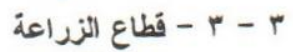

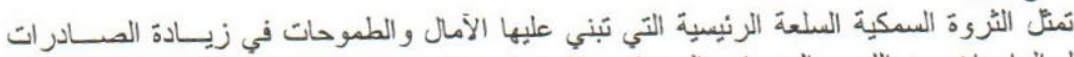

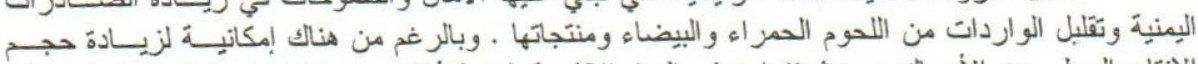

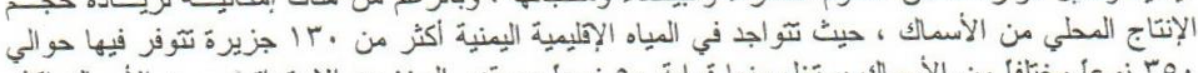

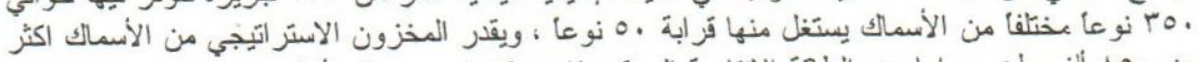

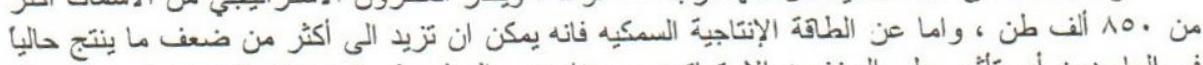

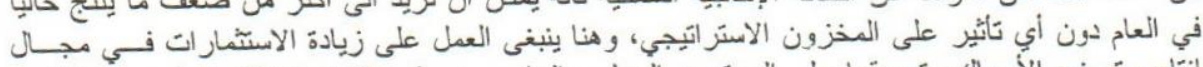

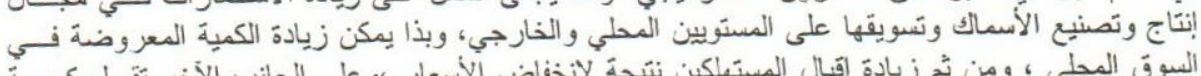

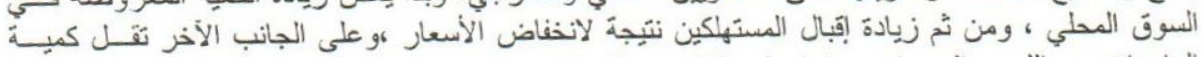

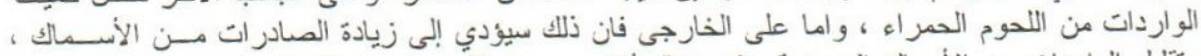

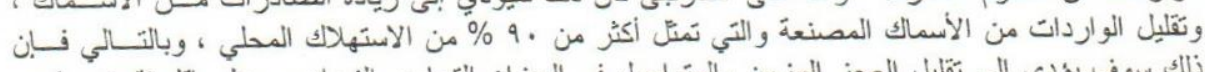

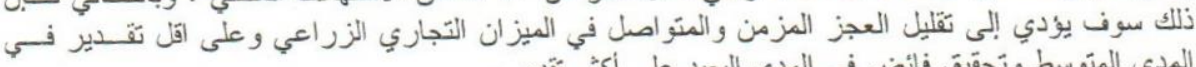

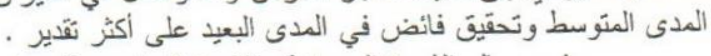

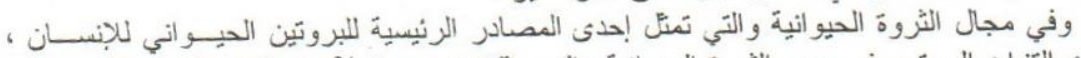

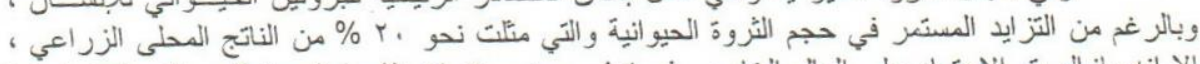

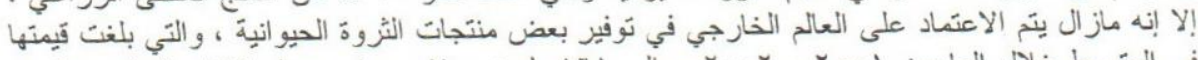

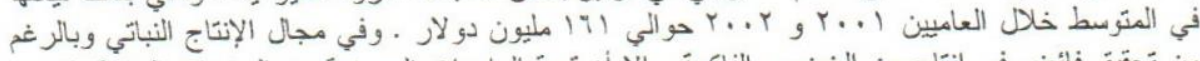

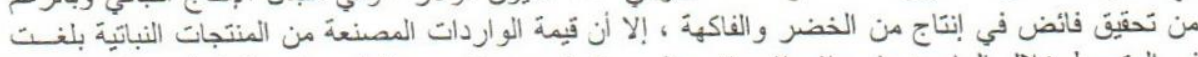

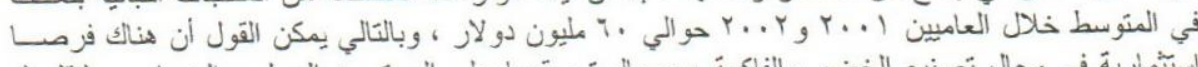

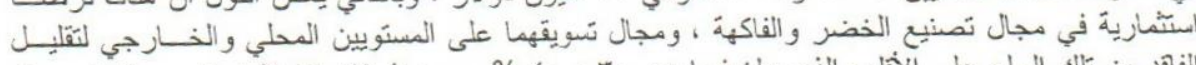

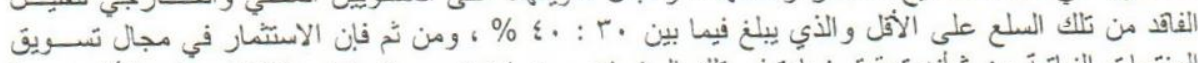

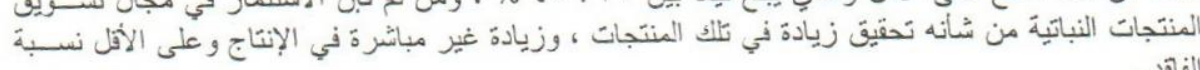

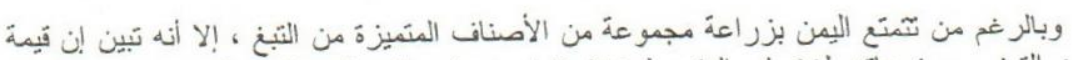

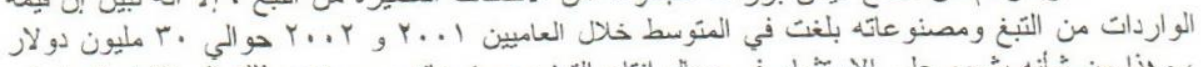

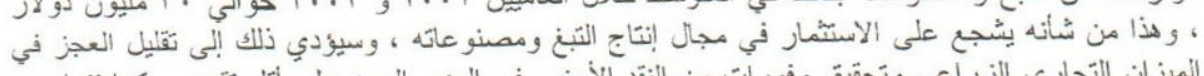

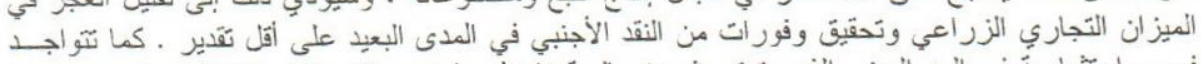

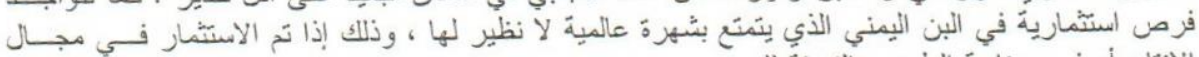

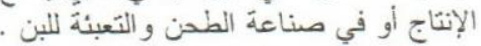

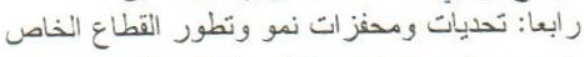

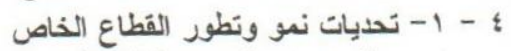

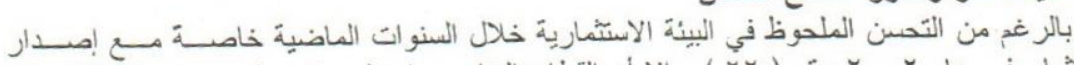

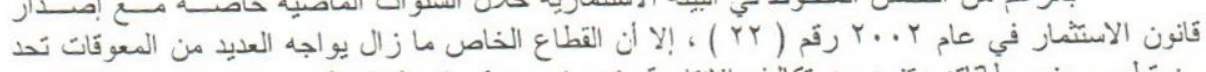

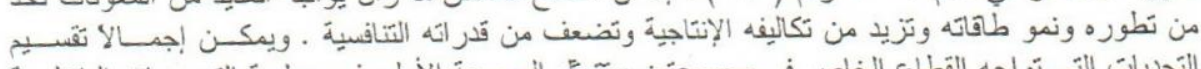

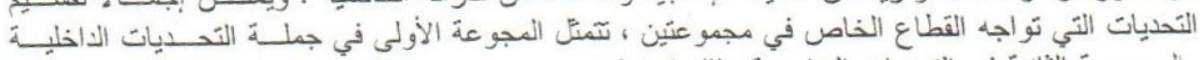

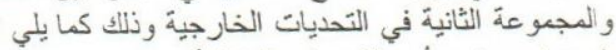
ـ - 1 - 1 - أهم التحديات الداخلية

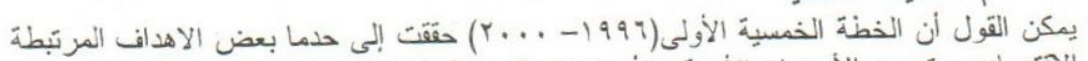

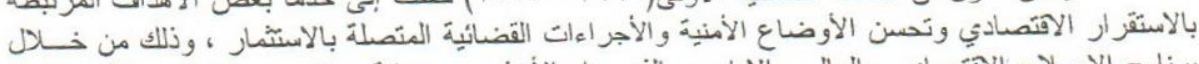

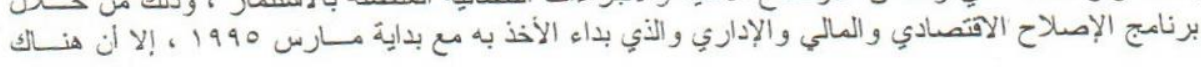




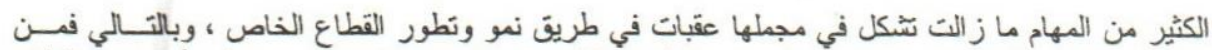

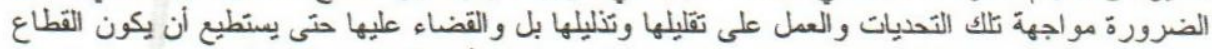

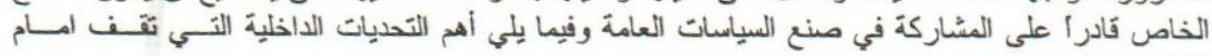

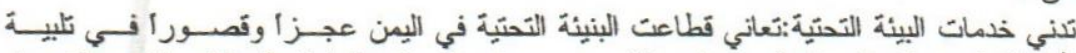

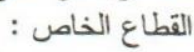

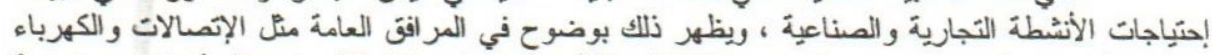

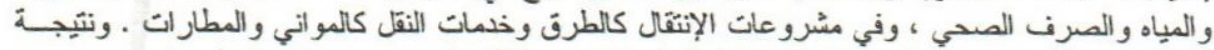

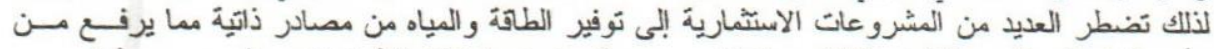

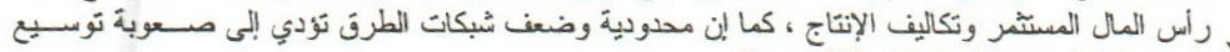

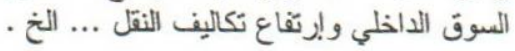

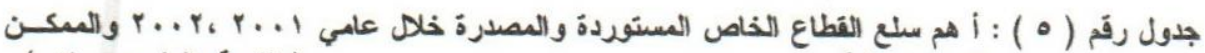

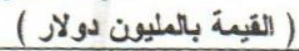

\begin{tabular}{|c|c|c|c|c|c|}
\hline \multicolumn{2}{|c|}{$r \ldots r$} & \multicolumn{2}{|c|}{$r \ldots 1$} & \multirow{2}{*}{ السنوات } & \multirow[b]{2}{*}{ ? } \\
\hline الصادرات & المواردات & الصادرات & المواردات & & \\
\hline- & rI & - & $\varepsilon, \mathrm{V}$ & الحِيو انات الحية & 1 \\
\hline$\cdot, 1$ & $\mathrm{~V} 0,1$ & $\cdot, 1$ & $7 V, 9$ & اللحوم ومنتجاتها & $r$ \\
\hline 1,9 & $\wedge 1, \mathrm{~V}$ & $r, \wedge$ & $\mathrm{v \cdot , \Lambda}$ & الألبان و البيض & $r$ \\
\hline $9 \cdot, 9$ & 7,0 & 07,7 & $r, 0$ & الأسماك و القَّريات و الرخويات & $\varepsilon$ \\
\hline$r 1,0$ & $71, \cdot$ & To,r & $0 \wedge, 1$ & الخضر او ات و الفاكهة & 0 \\
\hline$r, v$ & TY, T & 1,0 & $r V, \Lambda$ & التبغ ومصنو عاته & 7 \\
\hline 1,1 & or,r & $1, Y$ & $\varepsilon \mathrm{V}, \Lambda$ & زيوت وشحوم حيوانية ونباتيةية & v \\
\hline 1,7 & Or,,$\varepsilon$ & $r, V$ & $7 \cdot, r$ & الورق و الورق المقوب & $\Lambda$ \\
\hline$\cdot, r$ & $\leqslant r, r$ & $\cdot, 1$ & $r \Lambda, r$ & الغزل و المنسوجات & 9 \\
\hline$\cdot, r$ & $11, \cdot$ & $\cdot, r$ & IY,V & الالات المكتبيةً & 1. \\
\hline 0,1 & $9, \wedge$ & 7,1 & $1 Y, 1$ & أغذِية الحيو انات ما عدا الحبوب & 11 \\
\hline$\cdot, r$ & rr, & - & $Y_{\cdot, \underline{L}}$ & بذور وثُمار زينه & IT \\
\hline$r, \mathrm{r}$ & $r, \wedge$ & $r, \cdot$ & $r, q$ & مو اد خام حيو انيِة ونباتَِية & ir \\
\hline$\cdot, 7$ & 11,7 & $\cdot, 0$ & $\Lambda, \wedge$ & الأثاث وتو ابعها & $1 \leqslant$ \\
\hline- & $1, \varepsilon$ & - & $\cdot, 9$ & لو ازم السفر و الحقائب & 10 \\
\hline- & $0 \leqslant, 1$ & $\cdot, 1$ & $\leqslant \S, \wedge$ & المصنو عات المطاطية و الخشبيةَ و الفلين & 17 \\
\hline $10, \mathrm{~V}$ & $10, r$ & $1 r, q$ & - & الجلود والأحذِية & IV \\
\hline $107, \varepsilon$ & $07 r, r$ & 117,1 & $\varepsilon \wedge Y, r$ & & 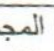 \\
\hline 0 & $r \cdot$ & $r, \varepsilon$ & $r$. & الإجمالي العام & \\
\hline
\end{tabular}

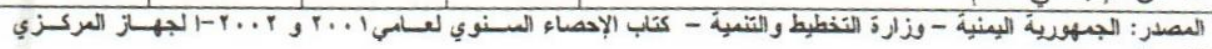

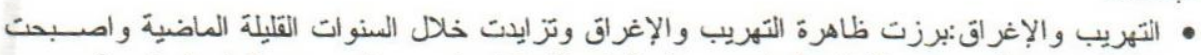

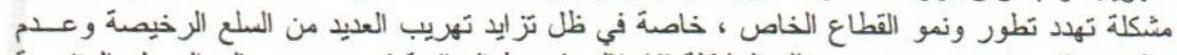

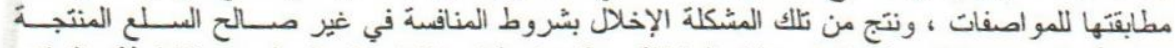

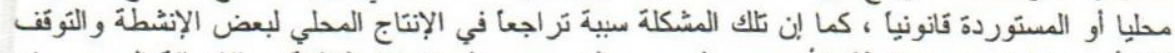

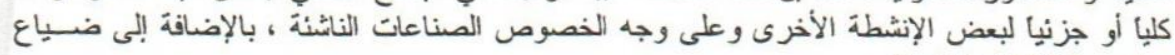

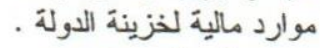

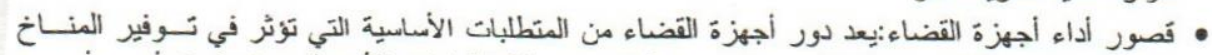

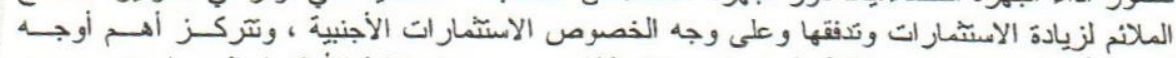

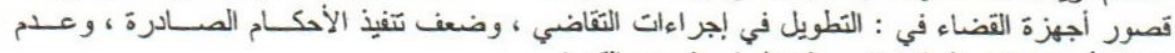

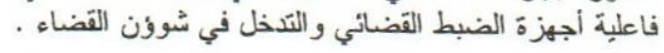




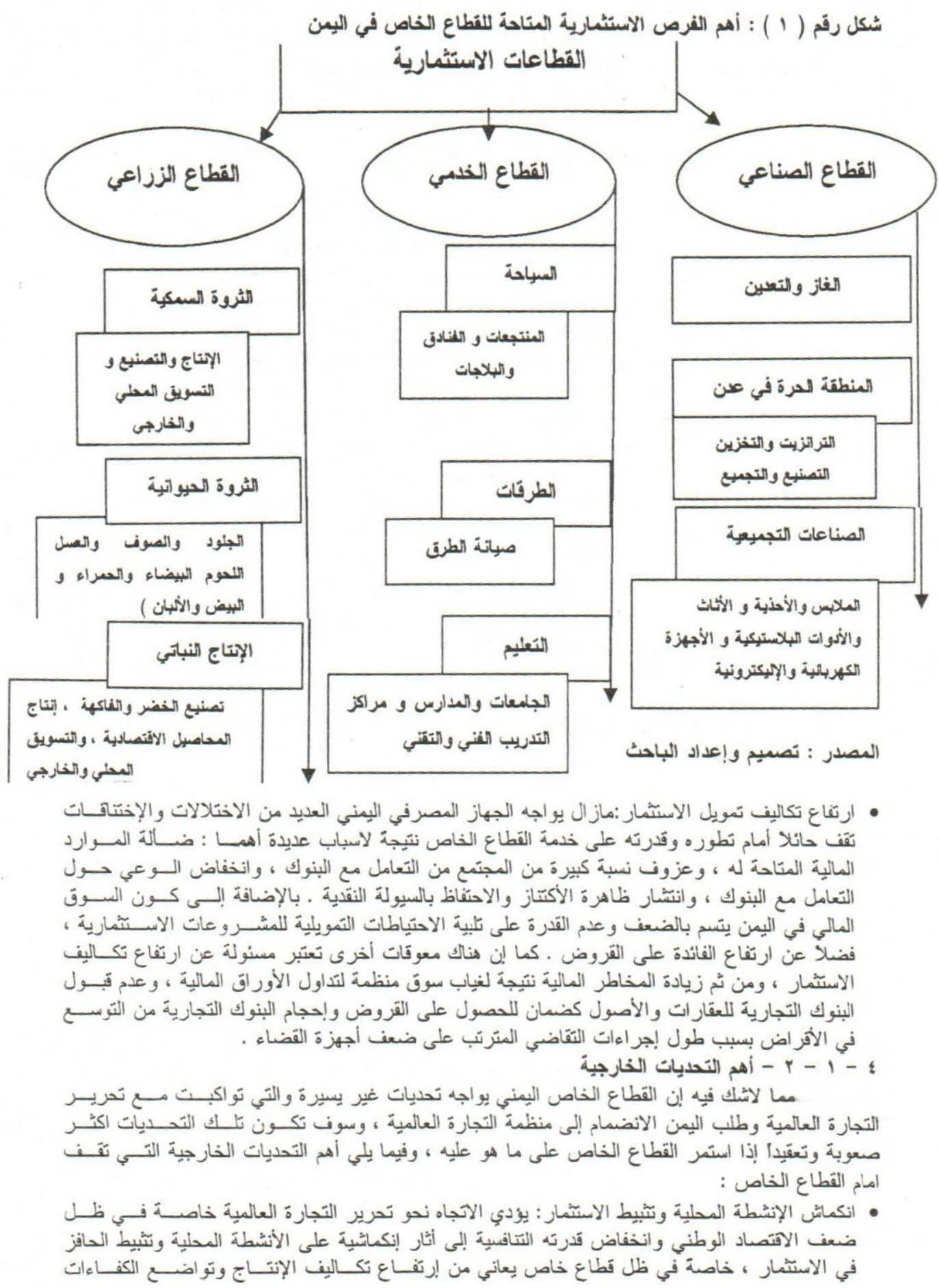




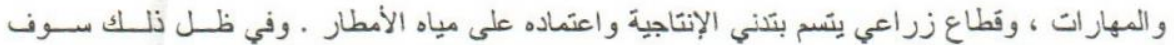

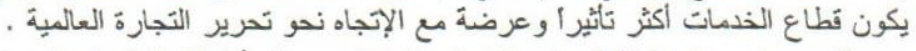

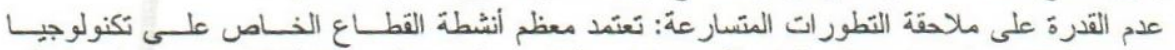

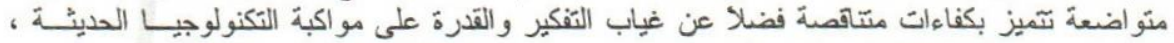

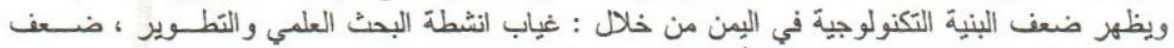

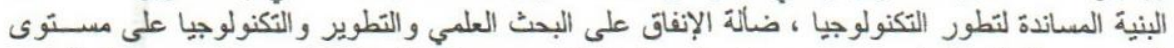

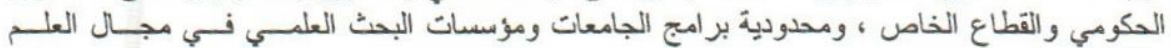

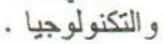

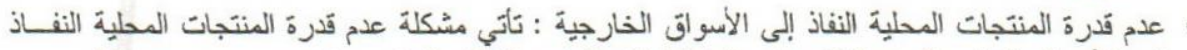

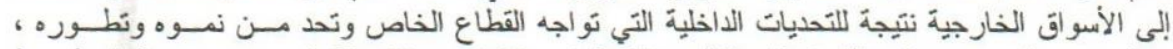

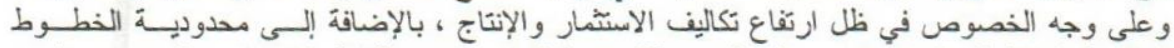

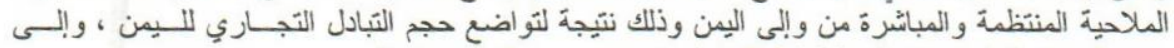

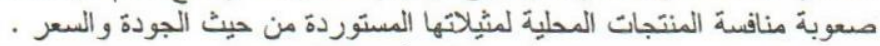

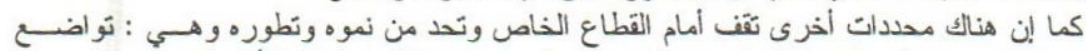

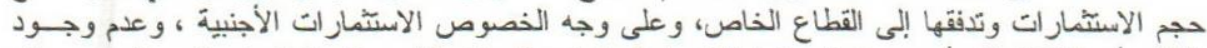

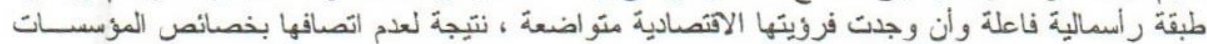

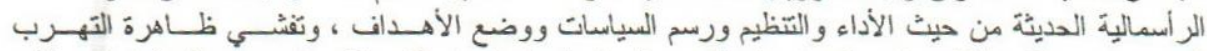

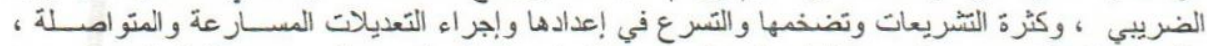

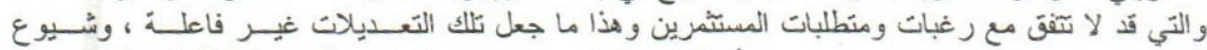

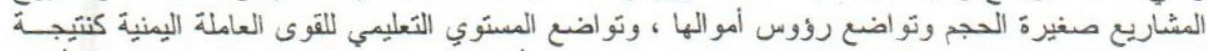

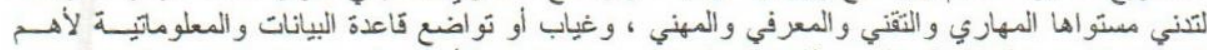

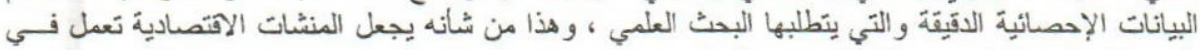

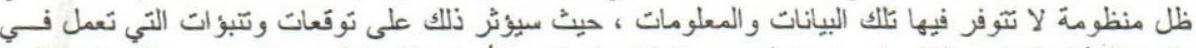

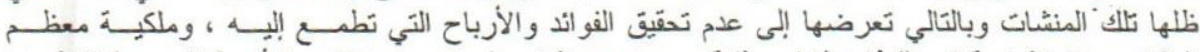

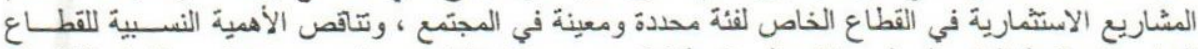

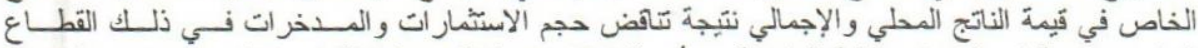

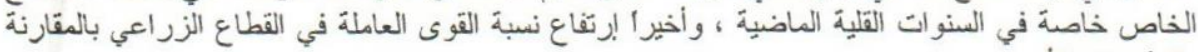

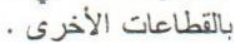

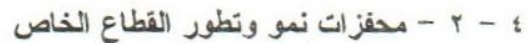

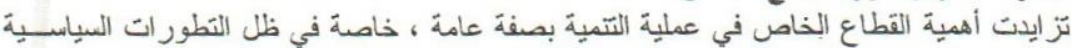

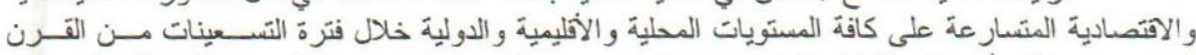

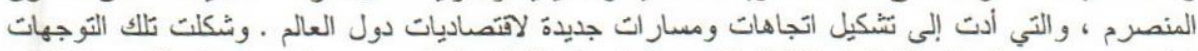

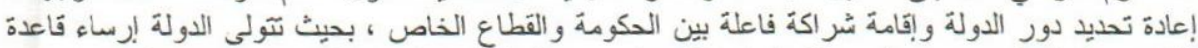

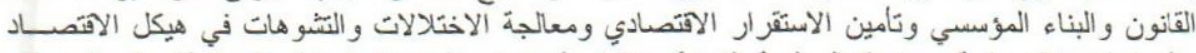

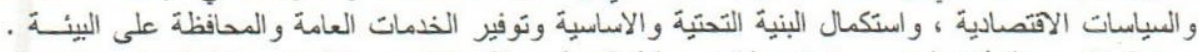

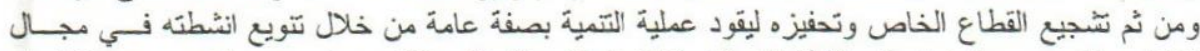

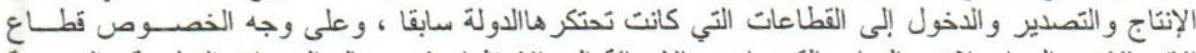

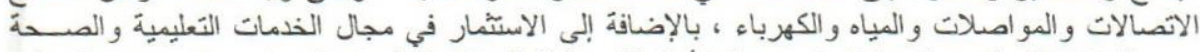

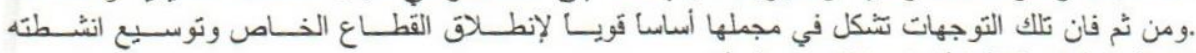

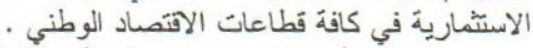

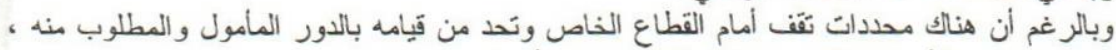

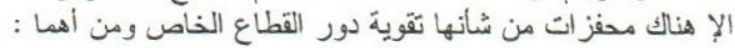

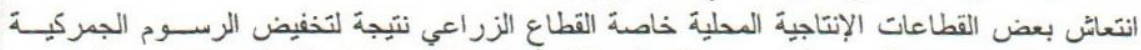

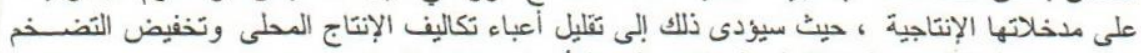

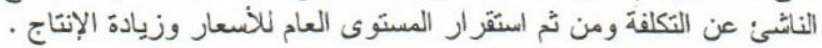




\section{6\&St}

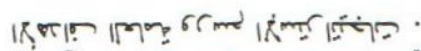

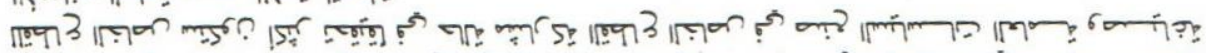

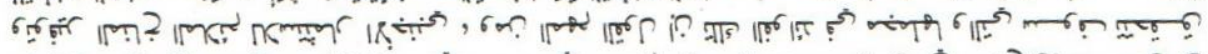

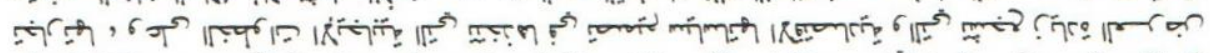

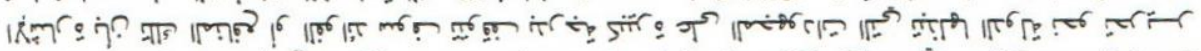

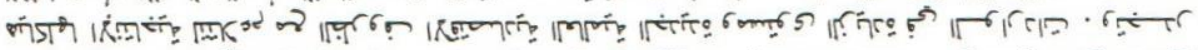

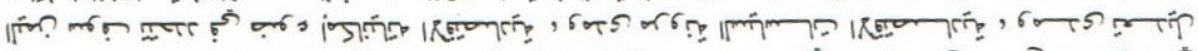

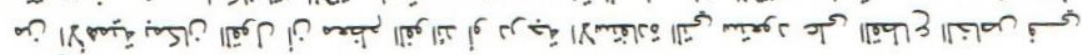

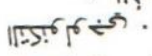

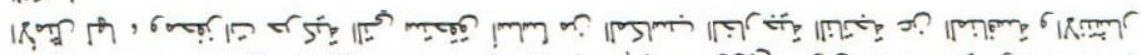

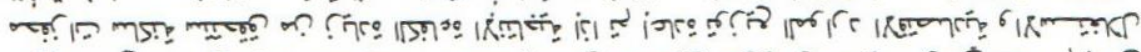

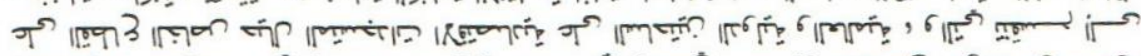

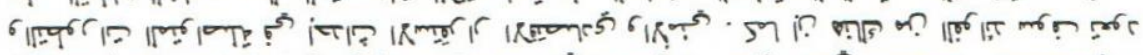

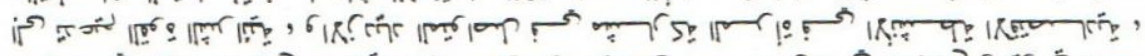

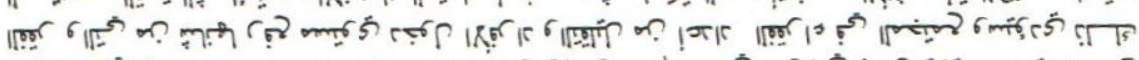

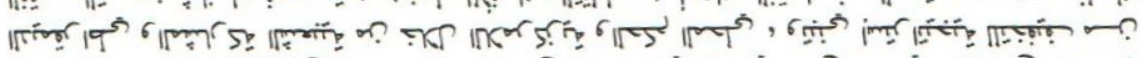

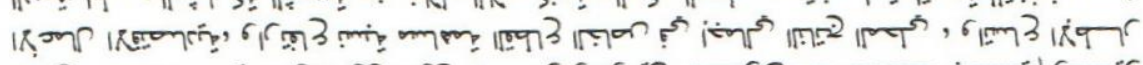

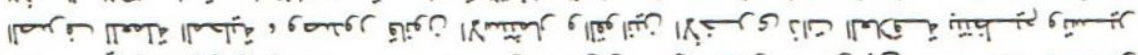

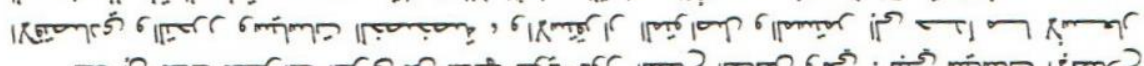

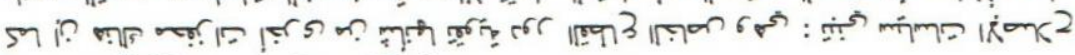

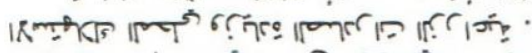

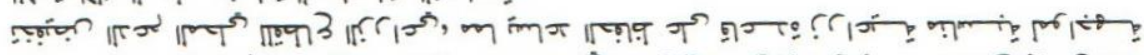

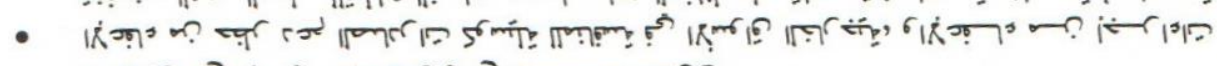

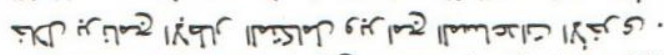

|

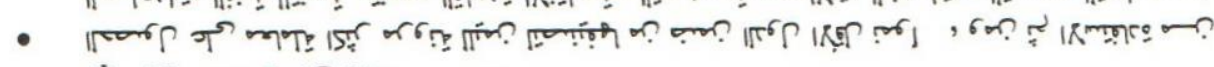
की

10.4

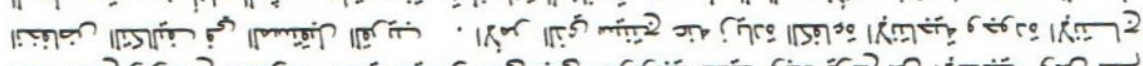

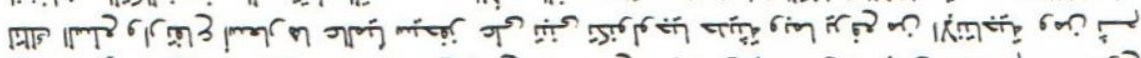

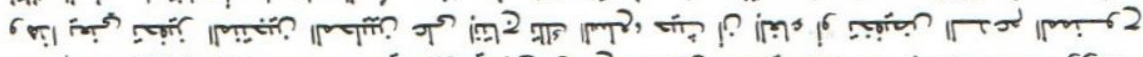

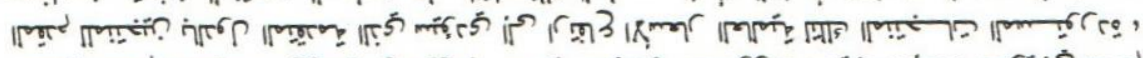

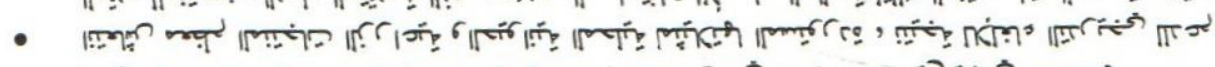
i

iह

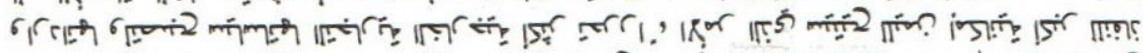

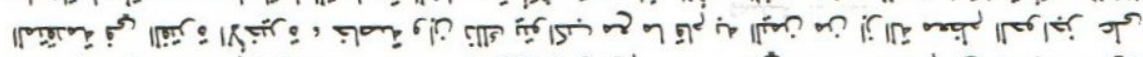

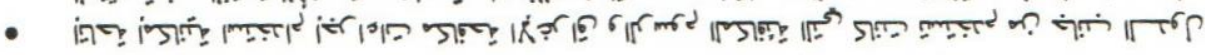
IIएक्णir.

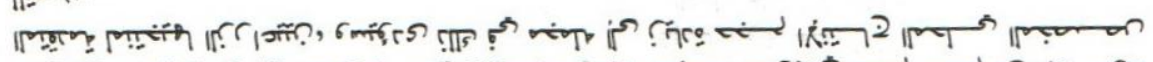

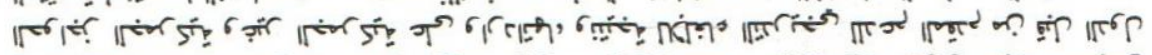

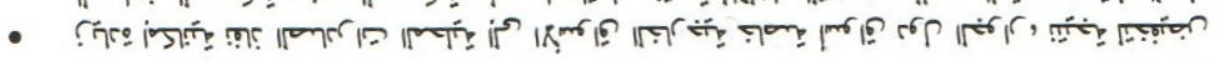


خامسا : آليات مشاركة القطاع الخاص في صنع السيلسات العامة

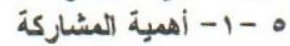

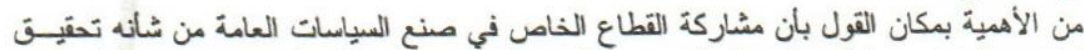

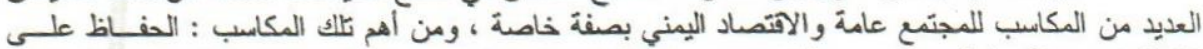

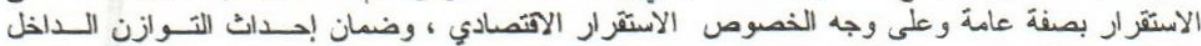

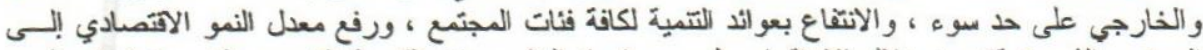

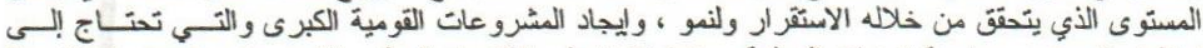

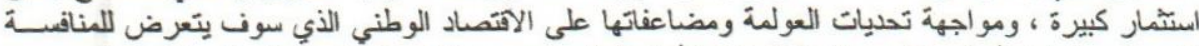

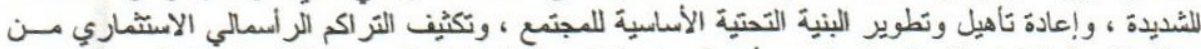

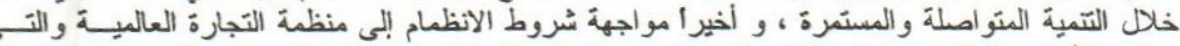

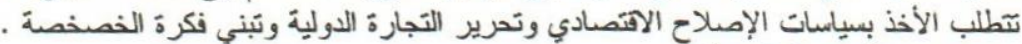

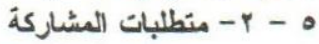

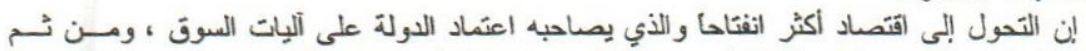

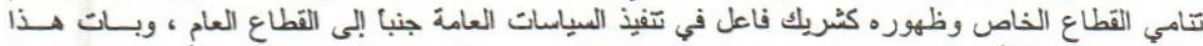

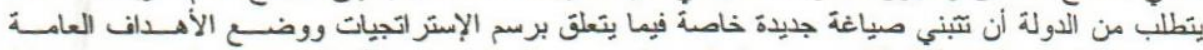

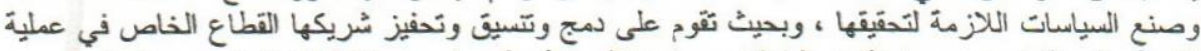

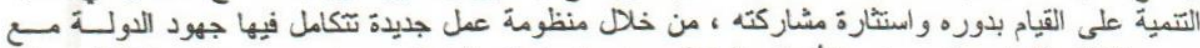

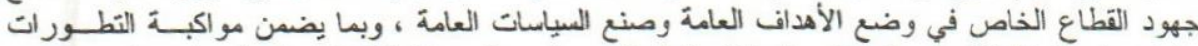

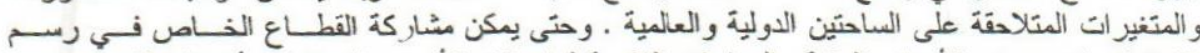

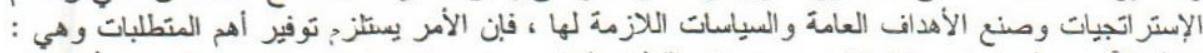

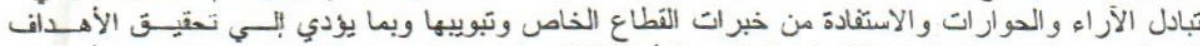

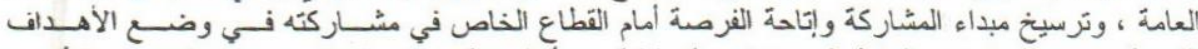

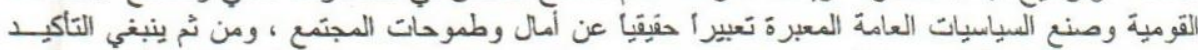

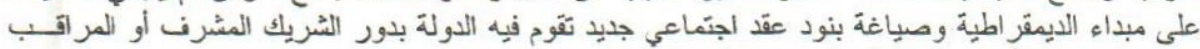

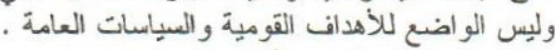

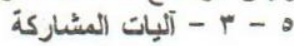

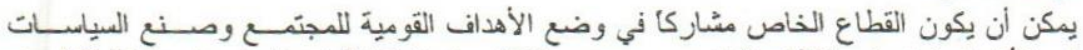

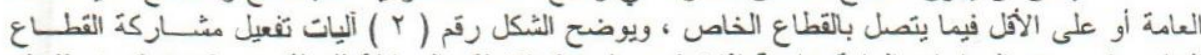

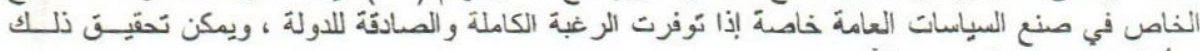

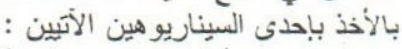

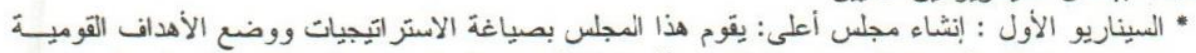

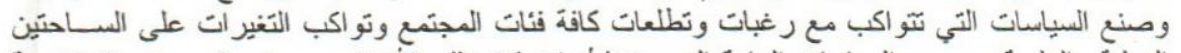

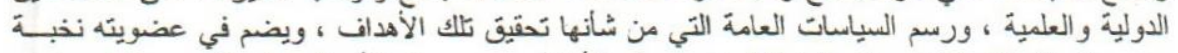

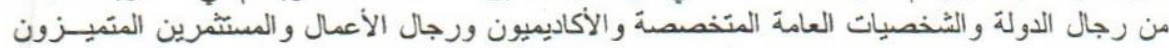

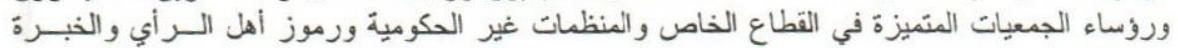

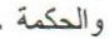

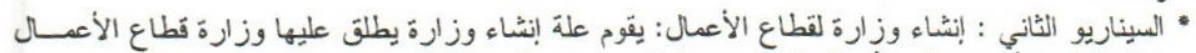

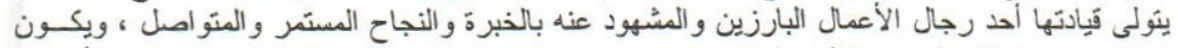

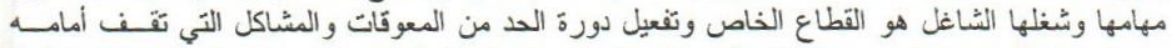

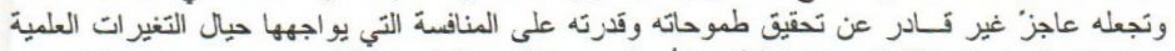

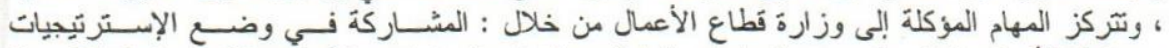

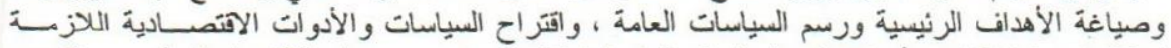

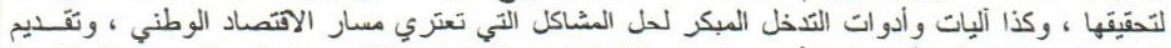

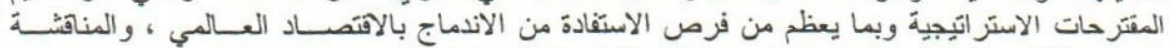

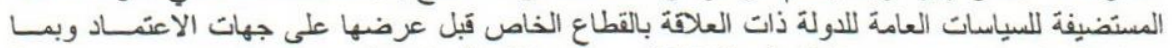

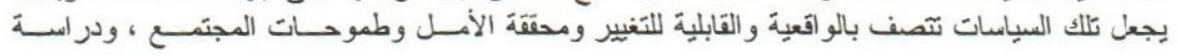




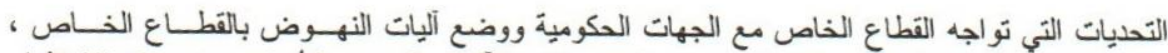

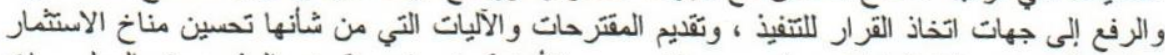

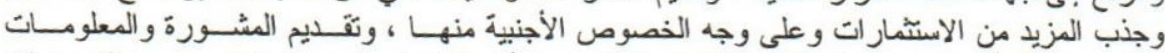

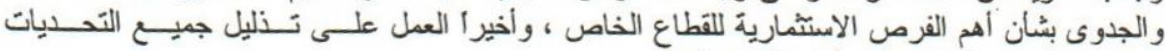

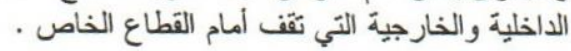

شكل رقم ( r ) : آليات مشاركة القطاع الخاص في صنع السياسات العامة
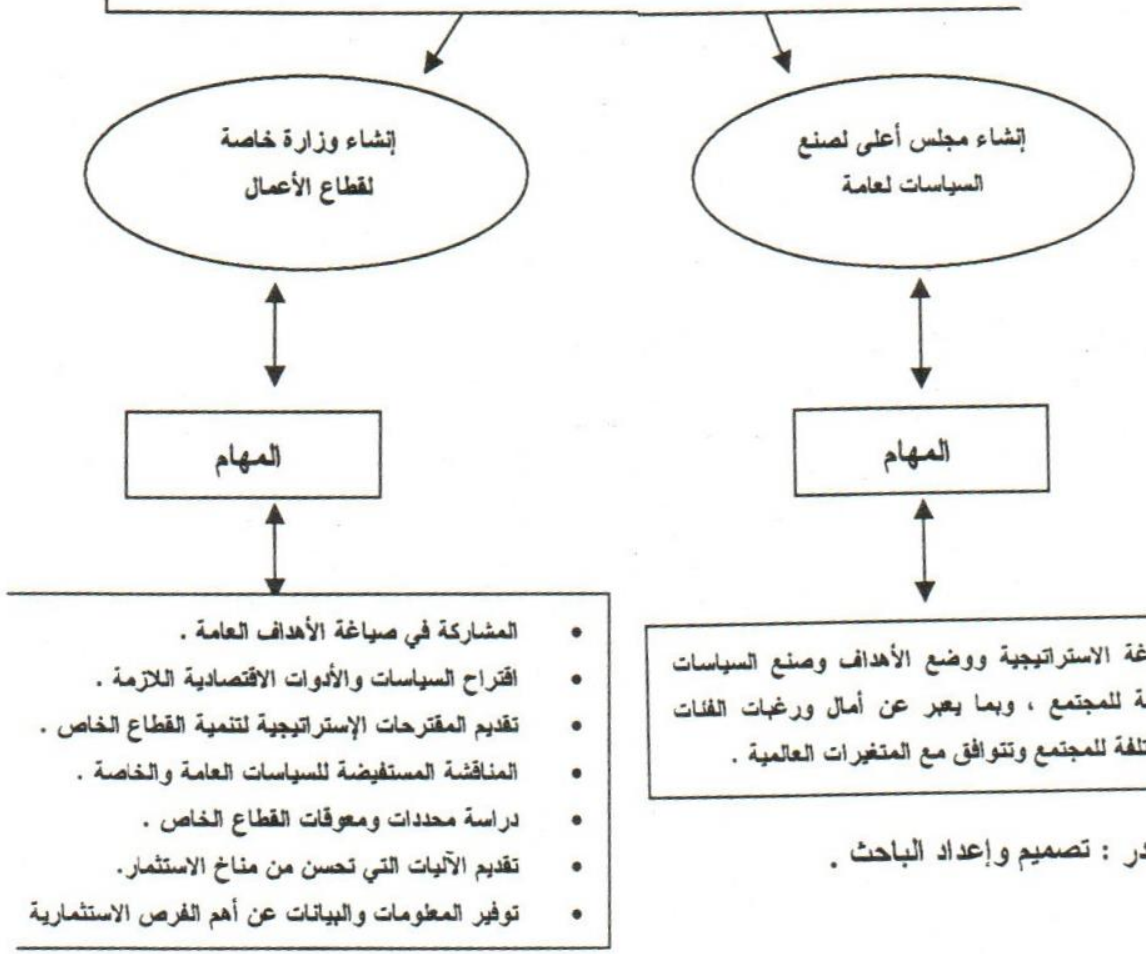

صباغة الاستراتيجية ووضع الأهاف وصنع السباسات

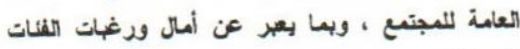

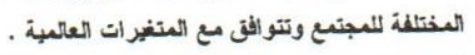

المصدر : تصميم و إعداد الباحث .

• خامسا : أهم التوصيات

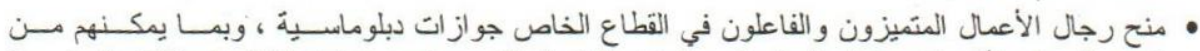

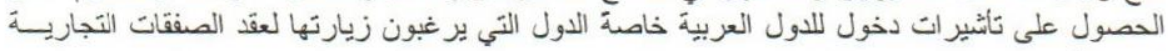
دون عناء .

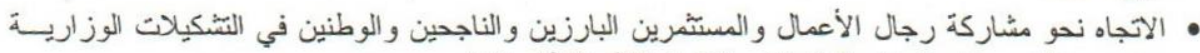

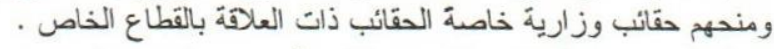

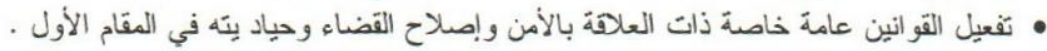

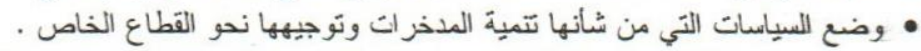

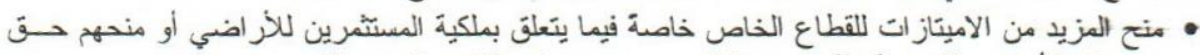

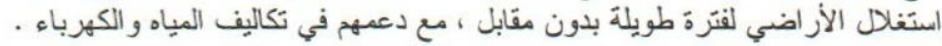

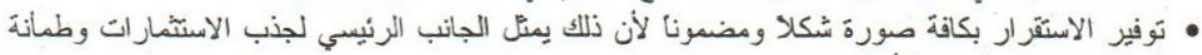

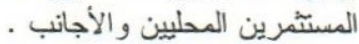

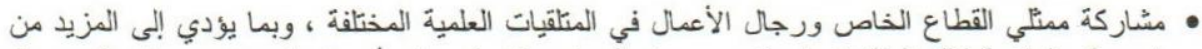

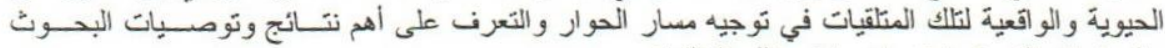

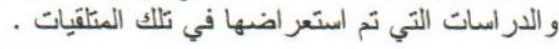


• العمل على أن نكون الاستر اتيجيات والأهداف و السياسات واضحة المعالم والتفسير .

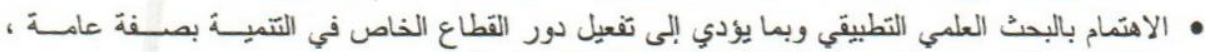

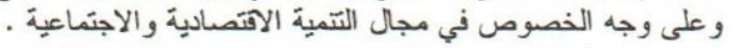

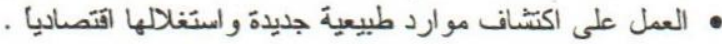

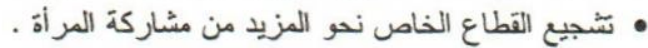

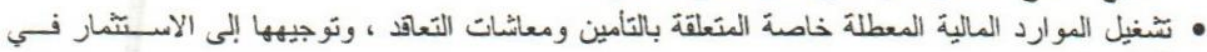

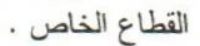

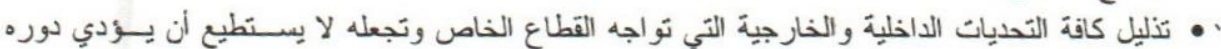
بفاعلية . باليل كانة

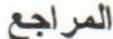

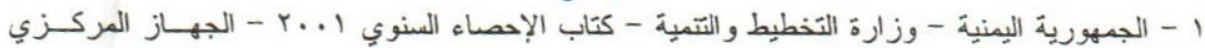

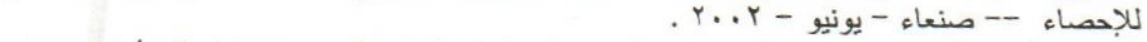
r - الجمهورية اليمنية - الفرص الاستمارية في اليمن - الهيئة العامة للاستمار - - الطبعة الأولى - يناير . r...

r - الجمهورية اليمنية - وزارة المالية - قطاع التخطيط و المتابعة - نشرة إحصائية مالية حكومية - نشرة

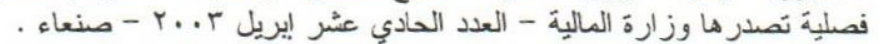

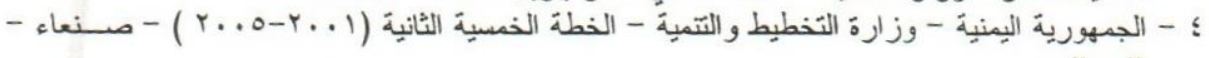
. r. r

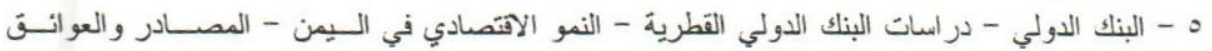

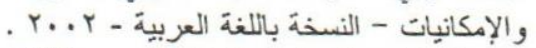

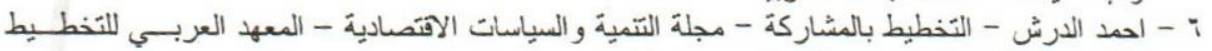

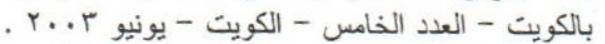

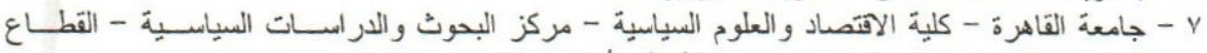

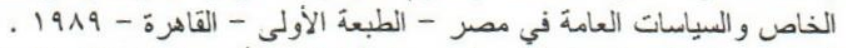

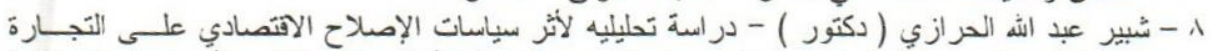

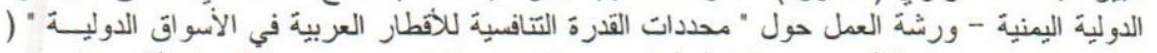

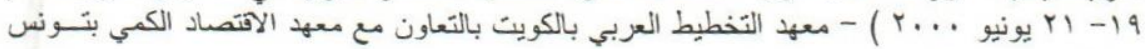

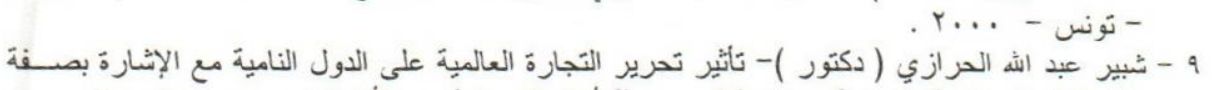

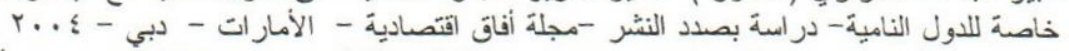

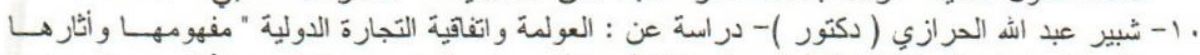

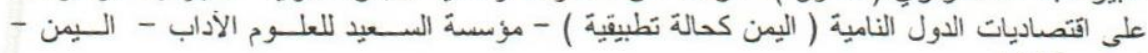

\section{PRIVATE SECTOR PARTCIPATION IN YEMEN NATIONAL ECONOMY}

Shobeer A. A. Elharazi

Dept. of Agric. Economic, Fac. of Agric., Sanaa Univ.

\section{ABSTRACT}

The objective of this study is to determine the tools that help the private sector in playing an important role in Yemen national economy. This study used the secondary data and descriptive statistical methods. The study consists of the following parts:the importanance of the private sector, its tools, different obstacles and its role in the Yemen national economy such as Gross Demostic Product ( G D P), invesments, savings, forigen trade ,the important available investment opportunties for private sector, concentraints and the importance of private sector in Yemen national economy. The study implies some recommendations about the role of private sector in the Yemen national economy. 